Review

\title{
Overview of follicle stimulating hormone and its receptors in reproduction and in stem cells and cancer stem cells
}

\author{
Swati Haldar ${ }^{1,2}$, Himanshu Agrawal ${ }^{1}$, Sarama Saha ${ }^{3}$, Alex R. Straughn ${ }^{4}$, Partha Roy ${ }^{1}$, Sham S. Kakar ${ }^{\circledR}$ \\ 1. Molecular Endocrinology Laboratory, Department of Biosciences and Bioengineering, Indian Institute of Technology Roorkee, Uttarakhand 247667, India \\ 2. Current address: Drug Discovery and Development Division, Patanjali Research Institute, Haridwar, Uttarakhand 249405. \\ 3. Department of Biochemistry, All India Institute of Medical Sciences Rishikesh, Uttarakhand 249203, India. \\ 4. Department of Physiology, James Graham Brown Cancer Center, University of Louisville, Louisville, KY 40202, USA. \\ $\triangle$ Corresponding author: Sham S. Kakar, Ph.D., MBA, Professor, Department of Physiology and James Graham Brown Cancer Center, 500 South Floyd Street, University of \\ Louisville, Louisville, KY 40202. Phone (502) 852-0812; E-mail: sham.kakar@louisville.edu. \\ (c) The author(s). This is an open access article distributed under the terms of the Creative Commons Attribution License (https://creativecommons.org/licenses/by/4.0/). \\ See http:/ /ivyspring.com/terms for full terms and conditions.
}

Received: 2021.06.11; Accepted: 2021.10.21; Published: 2022.01.01

\begin{abstract}
Follicle stimulating hormone (FSH) and its receptor (FSHR) have been reported to be responsible for several physiological functions and cancers. The responsiveness of stem cells and cancer stem cells towards the FSH-FSHR system make the function of FSH and its receptors more interesting in the context of cancer biology. This review is comprised of comprehensive information on FSH-FSHR signaling in normal physiology, gonadal stem cells, cancer cells, and potential options of utilizing FSH-FSHR system as an anti-cancer therapeutic target.
\end{abstract}

\section{Introduction}

Gonadotrophs of the anterior pituitary gland synthesize and secrete follicle stimulating hormone (FSH) in response to stimulation by the hypothalamic gonadotropin releasing hormone [GnRH also referred to as luteinizing hormone releasing hormone (LHRH)] [1]. FSH is a glycoprotein and plays an important role in: growth, development, pubertal maturation, and reproductive physiology $[2,3]$. It is a $35.5 \mathrm{kDa}$ heterodimeric protein that shares structural similarity with other glycoprotein hormones of pituitary and placental origin such as luteinizing hormone (LH), thyroid-stimulating hormone (TSH), and human choriogonadotropin hormone (hCG) $[1,4]$. FSH has a functionally indispensable 96 amino acid alpha- (a-) subunit that is common to LH, TSH and hCG, in addition to a structurally unique beta- $(\beta-)$ subunit [5,6] (Figure 1).

Functional specificity of FSH is provided by its $\beta$-subunit that ensures FSH interaction specifically with FSH receptor (FSHR) [7]. However, some computational and crystallographic studies have noted the interaction of the a-subunit with FSHR, suggesting that both $\alpha-$ and $\beta$ - subunits interact with surface receptors [8]. The constituting oligo- saccharides, namely: $\mathrm{N}$-acetylglucosamine, galactose, $\mathrm{N}$-acetylgalactosamine, mannose, and sialic acid, are attached to both subunits by covalent bonding via asparagine through N-linked glycosylation $[9,10]$. Glycosylation facilitates hormonal participation in protein folding, dimer stability, and secretion process, in addition to influencing metabolic clearance and receptor activation [11]. Like other glycoproteins, sialic acid heterogeneity leads to variations in glycoprotein composition and differences in the isoelectric charge of FSHR. Consequently, FSHR displays various chemical isoforms due to both structural variations and differences in charge. These glycoforms have been shown to have differential functional effects in in vitro studies. In an earlier study, Timosi et al. [12] demonstrated that different isoforms of FSHR function distinctly in rat granulosa cells. Seven isoforms that vary in sialic acid content were purified from the pooled anterior pituitary extracts with the help of high resolution chromatofocusing and affinity chromatography and analyzed for their potential to impact granulosa cells function during culture conditions. Less acidic FSHR isoforms induced the cAMP release, cytochrome P450 
aromatase mRNA expression, oestrogen synthesis and tissue type plasminogen activity (tPA) more strongly than more acidic form. FSHR isoform with high acidic content was found to be more potent in stimulating the mRNA synthesis of a-subunit of inhibin [12]. Recently, Loreti et al. [13] also found that different human FSHR sialic acid variants affect the endocrine activity and global gene expression in human ovarian granulosa like tumor cell line- KGN [13]. Less sialyated recombinant human FSHR were found to be more potent in stimulating the synthesis of oestradiol, progesterone and inhibin A. Similar to these observations, microarray data analysis also revealed that level of hormone sialyation differentially affected the expression of various gene relevant to the function of granulosa cells.

\section{Common $\alpha$-subunit}

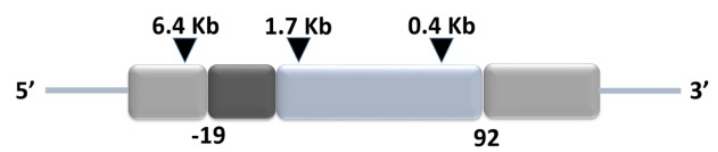

FSH $\beta$-subunit

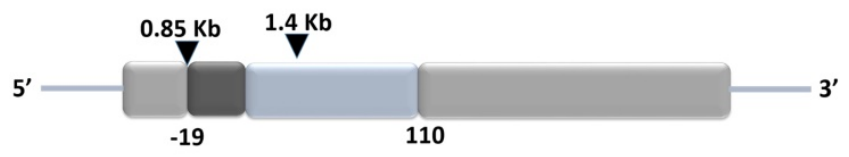

Untranslated region

Signal peptide

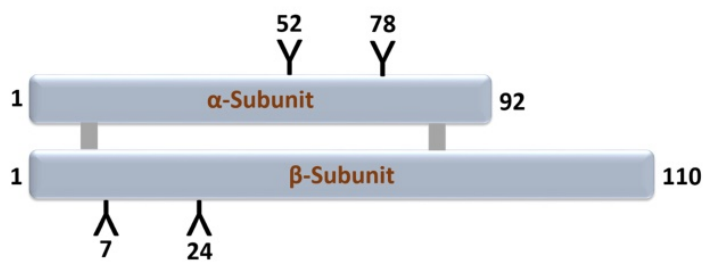

Figure 1. Schematic representation of structures of the common subunit $(\alpha-)$ and $\mathrm{FSH} \beta$ genes (upper panel) and of FSH protein (lower panel). The symbols ' $Y$ ' in the lower panel marks the approximate positions of the $\mathrm{N}$-linked carbohydrate side chains in the FSH molecules. Adapted from Huhtaniemi and Aittomaki [14]

Biological functions of FSH are activated through its interaction with its specific receptors (i.e. FSHR1). Human FSHR1 protein is composed of 695 amino acids polypeptide including the signal peptide. A mature FSHR1 protein of $76 \mathrm{kDa}$ molecular mass is expressed in Sertoli and granulosa cells [15]. Since FSHR1 possesses seven transmembrane helices, therefore it is also known as 7-Trans Membrane Receptor (7TMR). It consists of an N-terminal extracellular domain, 7-transmembrane domians, 3-extracellular loops, 3-intracellular loops and a C-terminal intra-cellular domain. The glycosylated extracellular domain has twelve leucine-rich repeats and consists of hormone-binding and signalspecificity sub-domains. A sulphated tyrosine at the $335^{\text {th }}$ amino acid position of a hinge loop in the signal-specificity sub-domain is responsible for the hormonal activity [7]. Disulfide bonds between highly conserved cysteine residues of the transmembrane domain stabilize the structure of FSHR1. The highly conserved Asp-Arg-Tyr triplet in GPCRs is believed to be responsible for signal transduction. However, in FSHR1, a Glu-Arg-Trp triplet is a variant of the highly conserved Asp-Arg-Tyr sequence normally found in GPCRs, which is believed to be responsible for signal transduction [16]. The transmembrane domain is followed by a short intra-cellular domain, which is rich in serine and threonine molecules that serve as potential phosphorylation sites during signal transduction. A comprehensive structure of FSHFSHR1 is depicted in Figure 2.

\section{Different isoforms of follicle stimutating hormone receptor (FSHR)}

In humans, the FSHR gene spans $52 \mathrm{Kbp}$ on chromosome 2 and consists of eleven exons and ten introns. FSHR gene exhibits four alternatively spliced forms (i.e. FSHR1, FSHR2, FSHR3 and FSHR4). Among these spliced forms, FSHR1 and FSHR3 are more recognized for their participation in various functions of FSH, including: cell growth, proliferation, and steroidogenesis [18,19]. Unlike FSH, which consists of a common a-subunit and a specific $\beta$-subunit, FSHR has different isoforms, implicating a diverse range of functions to be under its signaling influence. Therefore, a brief discussion on the functionalities of each of these FSHR isoforms in normal tissues is pertinent prior to coursing into the metabolic effects of their malfunctions. The remaining portion of this section has been dedicated towards understanding the functions performed by each of the four identified FSHR isoforms.

Among the four alternatively spliced isoforms of FSH receptors, FSHR1 transcript contains all the ten exons and is known as the major isoform that actively participates in steroidogenesis, follicular development, and spermatogenesis. It has a large N-terminal extracellular domain, seven a-helical transmembrane domains interconnected with alternating extracellular and intracellular loops, and an intracellular C-terminal tail [17]. The FSHR2 variant is structurally different from the FSHR1 splice variant, as evidenced by the deletion of the entire intracellular domain and a portion of the transmembrane domain. The FSHR2 transcript contains a truncated exon 10 , which is then joined to exon 11 (normally excised in FSHR1 transcript). Therefore, FSHR2 contains the extracellular domain and a portion of the 
transmembrane domain found in FSHR1 [19,20]. FSHR3 possesses an extracellular domain and a single transmembrane domain. In the FSHR3 transcript, exons 9 and 10 are spliced out, leaving exons 1-8 joined with exon 11 [21]. With only one transmembrane domain, FSHR3 is structurally different from both the FSHR1 and FSHR2 isoforms, with its overall topology more akin to the growth factor type I receptor. FSHR4 is dissimilar to all the three isoforms and exists as a soluble form of the receptor without any transmembrane domain. The exon structures of different splice variants of FSHR are depicted in Figure 3.

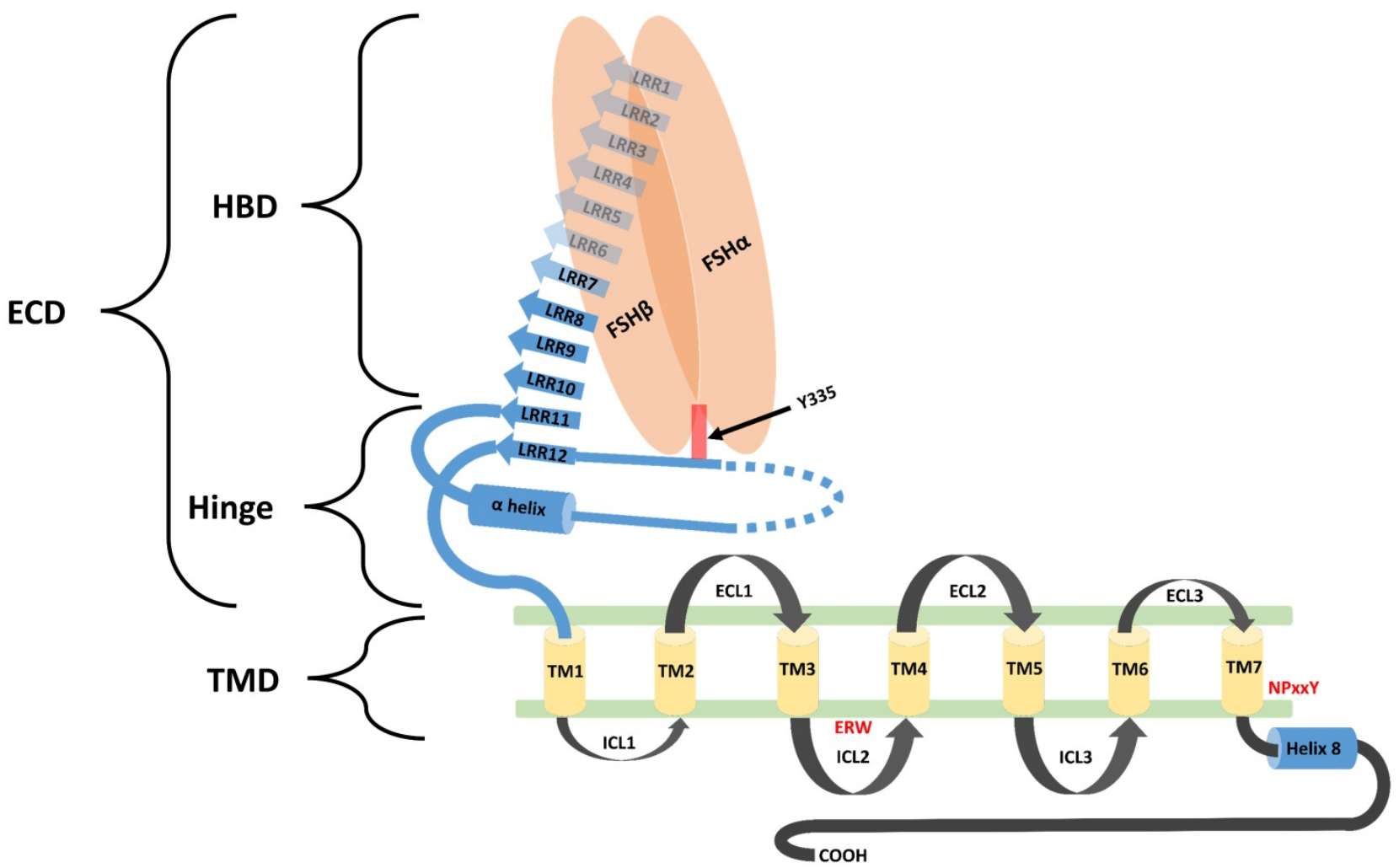

Figure 2. Schematic diagram representing the structural component of FSHRI. FSHR1 structure consist of an N-terminal extracellular domain, transmembrane domains and intracellular domains. Extracellular domain may be further divided into two subdomains, hormone binding domain (HBD) and hinge region. HBD comprises the ten 10 consecutive leucine rich repeats (LRR). Hinge region covers two other LRR, a hair pin loop and an alpha helix. A sulphated tyrosine at the 335 th amino acid position of a hinge loop in the signal-specificity sub-domain is responsible for the hormonal activity. A short intra-cellular domain rich in serine and threonine molecules serve as a potential phosphorylation sites during signal transduction. Leucine rich repeats are demonstrated by the blue colored arrows. The $\alpha$-Helix in the hinge region is shown as a blue colored cylinder. Transmembrane helices (1-7) are depicted as yellow colored boxes. FSH- $\alpha$ and FSH- $\beta$ subunits are demonstrated by orange ovoid shapes. ECL: Extracellular loop; ICL: Intracellular loop; ECD: Extracellular domain; TMD: transmembrane domain; HBD: Hormone binding domain. Re-drawn from Figure 2 of Pascali et al. [17].

\section{FSHR1 GPCR}

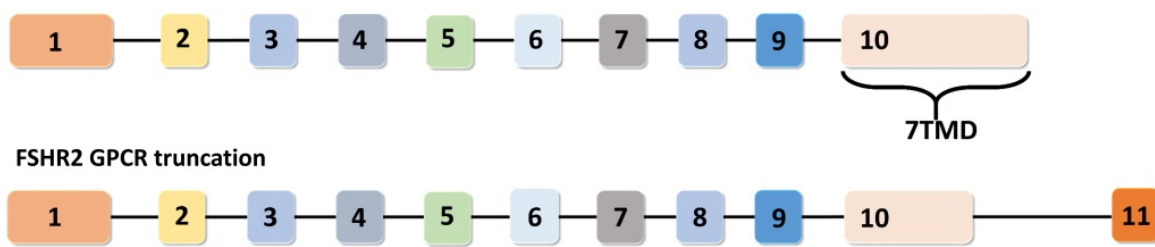

FSHR3 Growth Factor Type 1 receptor

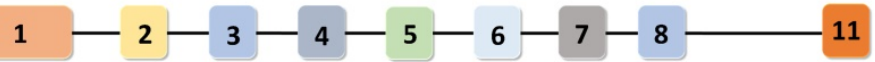

FSHR4 Soluble Type

$$
1-2-3-4
$$

Figure 3. Exon structures of FSHR splice variants. Canonical FSHR1 (GPCR) contains 10 exons, with the 7 transmembrane domains encoded by exon number 10 . FSHR2 (dominant negative isoform) is the truncated form of FSHR1, where exon 10 is truncated and joined with exon number 11 . In FSHR3 (Growth factor type 1 receptor), exons 9 and 10 are spliced out and the transcript is joined to exon 11. FSHR4 is considered to be a soluble-type receptor and only contains exons $1-4$. Adapted from Bhartiya and Singh [19]. 
FSHR1 is a member of the G-protein-coupled receptors (GPCRs) family and activates the G-protein (Gs), resulting in the production of cyclic adenosine monophosphate (cAMP), which subsequently leads to the induction of various signaling pathways after the initial binding to FSH $[20,22]$. G-protein coupling to the FSH-FSHR1 complex is mediated by the intracellular domains of the receptor. These domains are also responsible for the induction of downstream signaling cascades. The cAMP/protein kinase A (PKA)/cAMP response element-binding protein (CREB) pathway is one of the most prominent pathways activated by the FSH-FSHR1 complex, which is responsible for expression of the genes responsible for the proper functioning of granulosa cells, like aromatase and inhibin-a, among others [23]. With the activation of cAMP/exchange protein, the cAMP/RAS-related protein 1 (RAP1) pathway is induced, leading to activation of the downstream phosphoinositide 3-kinase (PI3K) pathway [24,25]. Additionally, the FSH-FSHR1 interaction activates several kinases, such as: Src family kinases (SFKs), mitogen-activated protein kinases (MAPKs), and extracellular signal-regulated kinases (ERKs), which are the key factors in some of the crucial metabolic pathways $[20,26]$. The FSH-FSHR1 complex, in conjunction with epidermal growth factor receptor (EGFR), regulates RAS and ERK1/2 pathways [23]. From the information obtained from preclinical studies, the FSH-FSHR1 pathway has been associated with increased angiogenic potential of granulosa cells of the ovary, conducive for follicular maturation. It has been noted that the FSH-FSHR1 complex facilitates secretion of pre-angiogenic factors, such as platelet-derived growth factor (PDGF)- $\beta$ and vascular endothelial growth factor (VEGF) from granulosa cells, through transforming growth factor (TGF)- $\beta 1$ [27]. Although the effect of the FSH-FSHR1 pathway on VEGF expression requires more clarity, this initial observation is suggestive of the involvement of FSH-FSHR1 interaction in vascular development in most, if not all rapidly growing cell populations [28].

FSHR2 is a truncated form of FSH receptor and this truncation disrupts the intracellular portion of the receptor and negatively affects the downstream signaling process [21]. Although, FSHR2 binds FSH with a high affinity, however it fails to induce G-protein coupled signaling. As a result, it is referred as dominant negative receptor [29-31]. Failure to activate the usual G-protein-mediated signaling pathway observed in response to FSHR1 is attributed to the binding of FSHR2 to the inhibitory $G_{i}$, instead of the stimulatory $G_{\mathrm{as}}$ protein. Further research remains to be performed to understand the physiological significance of the FSHR2 splice variant.
FSHR3 possesses a distinguishing feature from FSHR1. It functions independently of cAMPcontrolled pathways [32]. FSHR3 exhibits a growth factor type properties by actively participating in the mitotic activity and cell proliferation in its target cells. FSHR3 activates the mitogen-activated protein kinaseextracellular signal-regulated kinase (MAPK-ERK) pathway in granulosa cells in a cAMP-independent manner [31-33]. The C-terminal portion of FSHR3 is equipped with a consensus sequence cognate for phosphorylation by MAPK $[18,34]$. FSHR3 mediated activation of MAPK-ERK pathway regulates the cell proliferation through calcium ion $\left(\mathrm{Ca}^{2+}\right)$ influx via modulation of $\mathrm{Ca}^{2+}$-dependent channels [34,35]. Proliferation of ovarian surface epithelial cells in response to FSHR3 mediated MAPK activation further confirms its mitogenic and proliferative functions [35,36]. The function of FSHR4 is not presently defined, although it is assumed that FSHR4 binds with FSH within the extracellular matrix to prevent the latter from binding to any of the other three FSHRs, a modus operandi similar to that of insulin-like growth factor (IGF)-1-binding proteins [37]. FSHR4 has also been suggested as a prohormone of the active molecule [36]. Expression of different FSHR isoforms indicates more than one pathway being modulated by FSH signaling. Therefore, multicascade functions from cell proliferation to cell differentiation by FSH-FSHR signaling can partly be attributed to the involvement of different variants of FSHRs [38].

\section{Role of FSH-FSHR signalling in stem cell modulation}

Existing literature suggests the presence of spermatogonial stem cells (SSCs) in the mammalian testis. Further, recent reports demonstrate that stem cells are localized in adult ovaries and undergo postnatal oogenesis, similar to spermatogenesis in the testis $[39,40]$. Concurrently, a minor population of very small embryonic stem cells (VSELs) have also been observed along with SSCs in the testis. These cells have been shown to express FSHR and respond directly to FSH $[41,42]$. In the following section, we enumerate on the current information regarding the role of FSH-FSHR signaling in ovarian and testicular stem cell.

\section{Function of FSH-FSHR signaling in ovarian stem cells}

In reproductive biology, a general dogma exists which states that the mammalian ovary contains a fixed number of follicles that are depleted progressively with the advancement of age and culminates in menopause. However, this belief has 
been challenged by the existence of stem cells in adult ovaries. Various groups have demonstrated the presence of ovarian stem cells in adult mammalian ovary and put forth a hypothesis in favor of ovarian stem cells (OSCs) for their role in neo-oogenesis and primordial follicular (PF) assembly, similar to that of SSCs in spermatogenesis. According to this hypothesis, the presence of OSCs leads to the regular assembly of follicles on ovarian surface epithelial/cortical regions and that the process of primordial follicle assembly from stem cells is regulated by FSH [43].

Menopause probably occurs due to an age-related compromise in the somatic niche and, under this situation, OSCs are unable to undergo differentiation, thus leading to menopause [44]. Despite a unanimous consensus on the existence of OSCs in adult ovaries, strong evidence in support of their function in neo-oogenesis and follicular assembly under in vivo conditions needs to be developed. Recent studies have demonstrated the localization of stem cells in adult mammalian ovary surface epithelium. The very first study that challenged the concept of a fixed reserve of follicles in females was reported by Tilly and his group [45] showing the presence of 5-8 $\mu \mathrm{m}$ OSCs in mouse ovarian surface epithelium (OSE). Consistent with this information, Virant-Klun's group demonstrated the existence of human embryonic stem cell marker, SSEA-4 positive small stem cells $(3-5 \mu \mathrm{m})$ that express various markers related to pluripotency and primordial germ cells [46]. Further, the same group reported the spontaneous differentiation of these stem cells into oocyte-like structure under in vitro conditions [47]. However, this concept of stem cells in adult ovaries is still not widely accepted and encounters certain technical challenges [19]. Stem cell populations have been isolated from different species, including: mouse, sheep, human, rabbit, and monkey, through gentle scraping of OSE. They are divided into two categories based upon the localization of the pluripotent marker protein OCT-4 [48-51]. VSELs expressed nuclear OCT-4, while slightly bigger OSCs showed a cytoplasmic localization of OCT-4. VSELs isolated from gonads spontaneously differentiated into the sperm and oocytes in vitro without any specific requirement of growth factor/ cytokine and thought to be developmentally equivalent of primordial germ cells - the natural precursor of gametes [52-54]. VSELs have a high nucleocytoplasmic ratio, possess a capacity for self-renewal and could differentiate into OSCs $[44,50]$. In contrast, OSCs were reported to undergo rapid cell division and formed germ cell nest in response to FSH treatment $[19,50,55]$. Treatment of mice with pregnant mare serum gonadotropin (PMSG, an FSH analogue) stimulated the proliferation of OSE, which promoted the assembling of fresh follicular cells beneath the OSE [55].

Both FSHR1 and FSHR3 were found to be expressed in sheep OSCs, whereas the epithelial cells were distinctly negative for any type of FSHR. An active transcription of FSHR3 was observed in OSCs in response to FSH within $3 \mathrm{~h}$, although FSHR1 levels remained unaffected [51]. Patel et al. [56] observed that OSCs in sheep respond to FSH through FSHR3 and as a result of this interaction, OSCs experienced proliferation and clonal expansion that led to the formation of a germ cell nest, which could differentiate into oocytes [56]. Since VSELs are quiescent in nature, Sriraman et al. [57] examined whether VSELs can survive chemotherapy treatment and examined their potential to initiate neo-oogenesis after treatment with FSH. Treatment of chemoablated ovary with PMSG for $48 \mathrm{~h}$ was found to significantly increase the number of VSELs. A similar effect of FSH treatment was also observed in mechanically isolated OSEs from the chemoablated ovary. OSE culture in the presence of $\mathrm{FSH}$ resulted in the formation of PCNA and OCT-4 positive germ cell nests and further supported the formation of oocyte-like structure [57]. In contrast, some studies reported the absence of stem cells in mouse ovaries and proposed that primordial follicles developed during fetal life are appropriate for oogenesis and that oocyte renewal does not occur during the adult life [58]. Similarly, Zhang et al. [59] also reported the absence of post-natal oogenesis using a genetically modified mouse model. Nevertheless, this continues to be a debatable issue that requires extensive exploration and contextual evidence.

The evidences prove the role of $\mathrm{FSH}$ in stimulating OSCs. Nevertheless, direct action of FSH on ovarian stem cells and its physiologic function can be demonstrated only through knockout/down and overexpression studies on FSHR. To the best of our knowledge, there is no study that deals with the knockout/down of FSH/FSHR to establish the physiological role of FSH/FSHR in ovarian stem cells. However, the results obtained from earlier animal knock down studies of FSH/FSHR clearly demonstrate the obligatory role of FSHFSHR in the female reproductive system [60]. Two groups have examined the effect of knockout of FSHR gene in mice $[61,62]$. These reports demonstrate that as expected FSHR-/- female mice were sterile with a markedly reduced level of estradiol and progesterone. Female FSHR-/- mice had a small size of uterus and impaired follicular maturation with absence of mature follicle. Furthermore, the size of several reproductive 
organs such as uterine, ovarian and vagina were also reduced. Nevertheless, knock-out studies directly establishing FSH action on OSCs are still awaited. However, gain-of-function in vivo models to understand FSH functioning in physiological context contributed significantly towards our understanding of the modus operandi of this critical molecular partnership [63].

\section{Function of FSH-FSHR system in testicular stem cells}

The process of spermatogenesis originates from SSCs and involves several sequential steps of cell proliferation and differentiation, which lead to the development of spermatozoa [64]. In addition, interaction of several growth factors and hormones with germ cells and Sertoli cells regulates the process of spermatogenesis that ultimately leads to the generation of a functional spermatozoa [65]. According to classical knowledge, two pituitary hormones, LH and FSH, play a significant role in spermatogenesis. LH stimulate the production and secretion of testosterone from the Leydig cells present in the interstitial space in the testis; whereas FSH either independently or in association with $\mathrm{LH}$ promotes the proliferation of Sertoli cells and facilitates the synthesis of various signaling molecules and nutrients that assist the initiation and maturation of functional spermatid.

Conversely, testosterone interacts with androgen receptors in Sertoli cells and regulates several responses involved in spermatogenesis [66,67]. In vitro studies have been conducted to delineate the role of FSH in the development of Sertoli stem cells. Both in vitro and in vivo studies suggest that FSH acts as an important mitogenic factor for Sertoli cells and stimulates their proliferation. Additionally, FSH also stimulates the synthesis of certain growth factors, like Glial cell line-derived neurotrophic factor (GDNF) and fibroblast growth factor 2 (bFGF2), in Sertoli cells that supports the proliferation and colonization by type A SSCs $[68,69]$.

Similar to VSELs reported in adult human ovaries, these cells have also been documented in the testis of humans and mice $[41,70,71]$. The presence of VSELs in the testis was first reported by Ratajczak's group [72]. VSELs in the testis exist as a subpopulation among the well-examined SSCs near the basal region of the seminiferous tubule. These were characterized in vivo using mouse testicular section based on the nuclear OCT-4 immunolocalization $[41,73]$. OCT-4 has two major isoforms namely OCT-4A (that reflect pluripotent state), and OCT-4B (that reflect differentiated state) [41,70]. VSELs are pluripotent in nature and express pluripotent nuclear
OCT-4A in the nucleus, whereas SSCs are found to express cytoplasmic OCT-4B [43]. The expression pattern of FSHR in mouse testicular VSELs and SSCs and the impact of FSH treatment on their stimulation have been recently examined using mice model in vivo [41]. Testicular VSELs were studied through flow cytometry and were found to be positive for stem cell antigen (SCA) and negative for lineage (LIN) and hematopoietic marker (CD45), thus characterized as [LIN-/CD45-/SCA-1 ${ }^{+}$]. FSH plays a crucial role in spermatogenesis and it has been confirmed that both VSELs and SSCs express FSHR, and further they respond to FSH treatment. According to this study, pluripotent VSELs are the most primitive stem cells in the testis and FSH acts directly on them through FSHR3, not through canonical FSHR1, to stimulate their asymmetric cell division to undergo self-renewal. These VSELs then further develop into SSCs through symmetric cell division, undergo clonal expansion, and eventually terminally differentiate into sperm. Consistent with these observations, a similar positive impact of FSH on sheep testicular stem cell stimulation was also observed by Bhartiya and her group [70]. VSELs can survive chemotherapy and their surge was found after treatment with FSH $(0.045 \pm 0.008 \%$ control Vs $0.1 \pm 0.03 \%$ FSH treatment). Additionally, it was also reported that VSELs may effectively restore spermatogenesis after the transplantation of cells that involve stem cell niche formation (i.e. Sertoli cells and/or bone marrow mesenchymal stem cells) [70]. Recently, James et al. [73] determined the presence of OCT-4A positive VSELs in the endometrial region of adult mouse uterus. These cells were also found to express various isoforms of FSH. Taken together, these studies clearly demonstrate that FSHRs are not exclusively expressed on granulosa and Sertoli cells, but on uterine stem cells to stimulate their self-renewal and proliferation as in testis and ovary, suggesting that FSH/FSHR system possibly plays a crucial role in reviving the gonadal stem cell population (which were believed to be non-existence). A schematic summarizing the mainpoints of these recent studies is depicted in Figure 4.

\section{Function of FSH-FSHR in cancer and cancer stem cells}

Cancer stem cells drive the cancer progression through modulating signalling pathways and regulating miRNAs to offer therapy resistance and promote metastasis [74-76]. FSH plays a significant role in facilitating this role of CSCs in malignancy. FSH has been reported to exhibit anti-apoptotic effect in OSCs by modulating stem cell signalling pathway [77]. Besides, FSH also promotes proliferation of OSCs 
by activating sphingosine kinase [78]. As reported above, both VSELs (with nuclear OCT-4) and OSCs (with nuclear OCT-4) are part of the ovarian stem cell population. OSCs are equivalent to SSCs in the testes and can spontaneously differentiate. OSCs express FSH and are thus responsive to FSH-FSHR signaling leading to: self-renewal, clonal expansion, neooogenesis, and primordial follicle assembly. Although VSELs exhibit stemness similar to that of embryonic carcinoma cells, they are relatively quiescent [79]. Nevertheless, chemoresistant VSELs could undergo oogenesis in mice in response to FSH. These findings warrant the investigation and generation of novel onco-fertility management strategies [39]. Accumulating body of evidence demonstrates that FSHR is expressed in different types of tumors, such as: prostate, ovarian, thyroid, neuroendocrine, pancreatic, pituitary, and soft tissue sarcomas [80]. FSHR3 signaling promotes the proliferation of ovarian cancer cells [35], implying the role of FSHFSHR signaling in tumorigenesis and identifying this pathway as a potential anti-tumorigenic therapeutic target. The occurrence of testicular germ cell tumors (TGCTs) due to developmental exposure to endocrine receptors is attributed to epigenetic alteration in VSELs, driving enhanced proliferation and compromised differentiation [81].

The major transcriptional regulatory pathways controlling stem cell signaling, cellular reprogramming that are responsible for cellular pluripotency are: Hedgehog, Ephrin, WNT, and certain microRNA pathways [82]. The core transcriptional factors of these pathways are a part of a complex protein-protein interaction-dependent network that maintains stem cell pluripotency by modulating their own expression to upregulate pro-pluripotency genes and inhibit pro-differentiation of genes. This transcription regulatory network is an effector matrix responsive to several kinase signal transduction pathways activated by intrinsic and extrinsic stimuli. OCT-4, a stem cell marker, is overexpressed in several types of human cancer and can induce resistance to chemotherapy and inhibition of apoptosis.

FSH-FSHR upregulates OCT4 expression in ovarian cancer stem cells, most likely through its regulation of GSK3 $\beta / \beta$-catenin and PI3K/Akt effector pathways $[77,83]$. Overexpression of OCT4 results in increased levels of Notch, Sox2, and Nanog, leading to expansion of $\mathrm{CD} 44^{+} / \mathrm{CD} 117^{+}$cells exhibiting stemness [77]. Moreover, FSH-FSHR-mediated upregulation of OCT4 and SNAIL through the ERK1/2 pathway results in epithelial-mesenchymal transition and invasion in epithelial ovarian cancer [84]. Further, FSH modulates ovarian stem cells through FSHR3 to stimulate potential self-renewal and clonal expansion [85]. The formation of cystic ovarian follicles depends on results from increased levels of $\mathrm{LH}$, and FSH signaling evident from the absence of follicles in transgenic mice in which FSH $\beta$ or FSHR genes are knocked out [86]. Therefore, proper functioning of the FSH-FSHR system is imperative for maintenance of gonadal stem cells in an effort to prevent them from triggering carcinogenesis. This regulation is exerted through various signaling cascades under the control of FSH. Notably, by stimulating phosphorylation of sphingosine kinase 1 (SphK 1) and 2 (SphK 2), FSH induces proliferation of ovarian cancer cells in epithelial ovarian cancer [78].

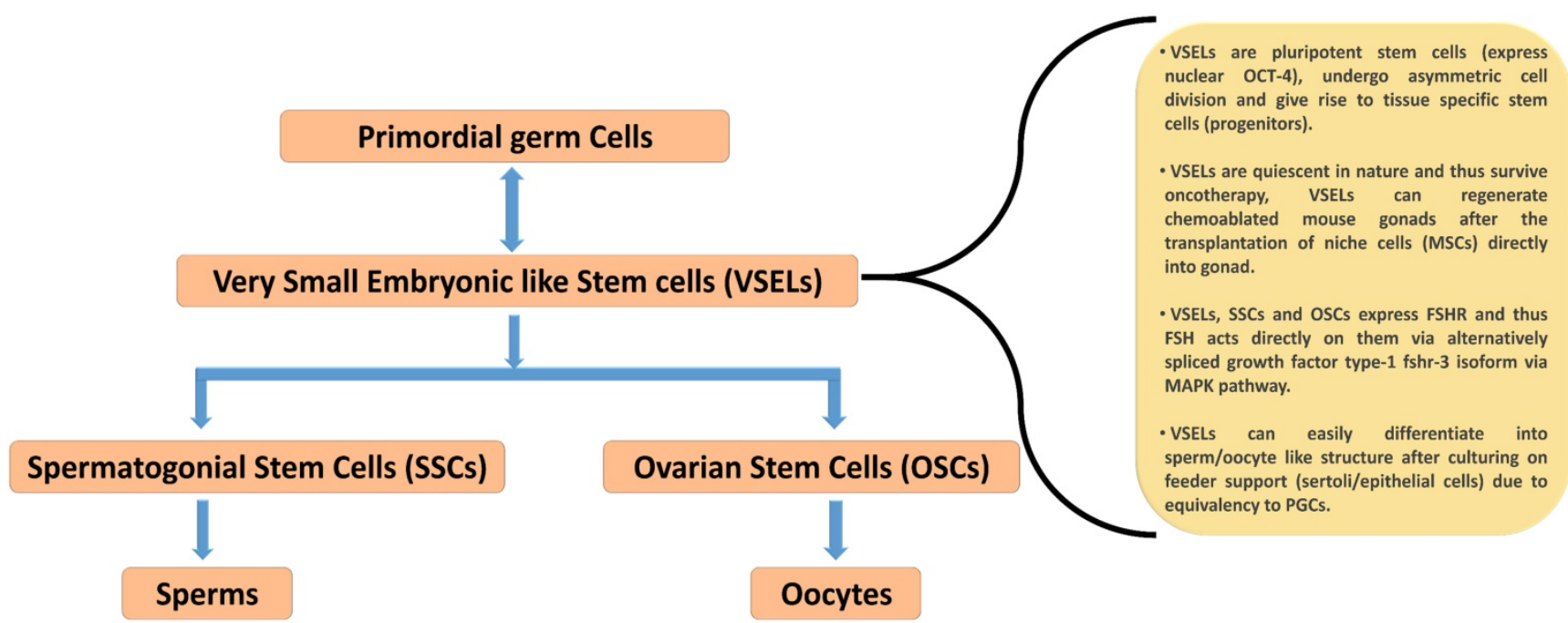

Figure 4. Schematic diagram representing the hierarchy of stem cells found in mammalian gonad and their prominent characteristics. VSELs are considered as developmentally equivalent to primordial germ cells due to their spontaneous differentiation into oocytes and sperm like structure during in vitro culture condition. VSELs are quiescent small sized stem cells, exist in gonads and give rise to a marginally bigger SSCs/OSCs that further differentiate into gametes by undergoing symmetrical cell divisions (according to the hypothesis put forward by Bhartiya et. al. (43). Re-drawn from Figure 6.2 of Bhartiya et al. [43]. 
Polymorphisms in the FSHR gene have been found to modulate the risk of testicular germ cell tumor formation. Polymorphisms in the coding region, such as: Ala ${ }^{307} \mathrm{Thr}$, and Ser ${ }^{680} \mathrm{Asn}$ in exon 10 of FSHR gene alone or in combination with polymorphisms in the promoter region $(-114 \mathrm{~T} / \mathrm{C}$ and $-29 \mathrm{G} / \mathrm{A}$ ) are reported to be associated with a reduced risk of the disease [87]. In contrast, homozygous $\mathrm{Ala}^{307} / \mathrm{Ser}^{680}$ alleles have been observed to increase the risk and recurrence of ovarian cancer [88]. Although the risk associated with different types of gonadal cancer with FSHR polymorphisms are unknown, therefore underlying mechanisms employed by these polymorphisms in modulating FSHR function require further explorations.

\section{FSH-FSHR signaling in malignant tumors}

A few, but conflicting reports are available regarding the FSH-FSHR signaling system pertaining to tumor malignancies [89,90]. However, a notable exception exists in such research efforts relating to ovarian cancer, for which a large body of evidence exists documenting the role of this system in disease pathogenesis [91-94]. FSH reduces the expressions of PDCD6 (programmed cell death gene 6) and DR5 (death receptor 5). As a consequence of this process, it is likely that apoptosis of epithelial ovarian cancer cells is inhibited. This observation is linked to the loss-of-function in the FSH-FSHR signaling during disease progression [95]. In contrast, in the case of serous ovarian cystadenocarcinoma, FSH augments the PI3K/AKT pathway and increases VEGF expression [96]. Likewise, FSH is involved in Gankyrin-mediated ovarian oncogenesis through the PI3K/AKT/hypoxia-inducible factor (HIF)-1a/cyclin D1 pathway [97]. FSHR-3 expression orchestrates the mitogenic and cellular proliferative activities of FSH, and is associated with epithelial ovarian cancer [36]. Overexpression of the receptor due to its association with: increased c-Myc, human epidermal growth factor receptor 2 (HER-2)/neu, and EGFR, as well as a reduction in prohibitin and $\mathrm{RIIb}$, facilitates the increase in cell proliferation and induces a concomitant aggressiveness of the carcinoma [94]. In this contest, several studies have shown an association of FSH-FSHR signaling with both a VEGFdependent and -independent manner in promotion of angiogenesis and the consequent cell proliferation and migration of ovarian cancer $[98,99]$.

\section{Recent updates for FSHR expression in different malignancies}

As mentioned above, the involvement of FSHFSHR signaling in malignancies in tissues other than gonadal cancers is limited. However, gradually accumulating evidence points towards the involvement of FSH-FSHR signaling in cancers of various tissues other than gonads. In this regard, a recent trial reporting FSHR expression in vascular endothelial cells in prostate, breast, and urothelium cancers are reported [100]. Studies on thyroid cancer suggest FSHR as a marker for malignancy [101,102]. Augmented FSHR expression is also observed in pituitary adenomas, adrenal tumors, and pancreatic neuroendocrine tumors [103,104]. Major studies validating FSHR expression in different types of cancers are presented in Table 1.

\section{Effector pathways: events and outcomes of FSH-FSHR activation}

\section{FSH-FSHR activated cytosolic signaling pathways}

For almost over two decades, FSH-FSHR has been believed to be acting through the Gas/cAMP/ PKA signaling pathway to mediate its biological actions in the target cells [109,110]. Interestingly, evidences show that FSH-FSHR system works through other pathways as well, and curiously, some of them are G- protein independent. Figure 5 schematically summarizes the $G$ protein-dependent and -independent signaling pathways that gets activated within the target cells by FSH-FSHR system.

Table 1. Major studies validating expression of FSHR in different types of tumor tissues

\begin{tabular}{|c|c|c|c|}
\hline Type of Tumor (No. of Patient) & Type of study, Aim & Results & Reference \\
\hline $\begin{array}{l}\text { Prostate (773), Breast (112), Urothelial (77), } \\
\text { Pancreas (67), Kidney (64), Colon (15), } \\
\text { Hepatocellular (15), Lung (15), Testicular } \\
\text { (8), Gastric (6), Ovarian (6) }\end{array}$ & $\begin{array}{l}\text { Retrospective, expression of FSHR in } \\
\text { different tumors }\end{array}$ & $\begin{array}{l}\text { Highly selective expression of FSHR on the surface of the blood vessels } \\
\text { (endothelium) of all tumors (uniform expression of FSHR in all tumors } \\
\text { with specific pattern, no expression in normal and inflammatory issues) }\end{array}$ & 100 \\
\hline Ovarian (156) & $\begin{array}{l}\text { Prospective, correlation of FSHR } \\
\text { expression and overall survival }\end{array}$ & Tumors overexpressing FSHR: decreased overall survival & 105 \\
\hline Ovarian (153) & $\begin{array}{l}\text { Retrospective, correlation of HER-2 and } \\
\text { FSHR expression and overall survival }\end{array}$ & $\begin{array}{l}\text { HER-2 expression related to an adverse impact on overall survival, only } \\
\text { in non FSHR expression (small sample size of HER-2 expression }\end{array}$ & 106 \\
\hline $\begin{array}{l}\text { Prostate (76), Lung (46), Breast (42), Colon } \\
\text { (34), Kidney (5) }\end{array}$ & $\begin{array}{l}\text { Retrospective, expression of FSHR } \\
\text { in different tumors, primary/metastatic } \\
\text { sites }\end{array}$ & $\begin{array}{l}\text { FSHR is expressed by the endothelium of blood vessels in the majority } \\
\text { of metastatic tumors (no specific pattern of expression identified } \\
\text { between primary and metastatic site, no expression identified in normal } \\
\text { and inflammatory issues) }\end{array}$ & 107 \\
\hline Kidney (50) & $\begin{array}{l}\text { Prospective, correlation of FSHR } \\
\text { expression with sunitinib therapy }\end{array}$ & $\begin{array}{l}\text { FSHR-positive stained vessels were on average } 5 \text { - and } 8 \text {-fold higher in } \\
\text { responders and patients with stable disease, respectively, than in } \\
\text { nonresponders }\end{array}$ & 108 \\
\hline
\end{tabular}




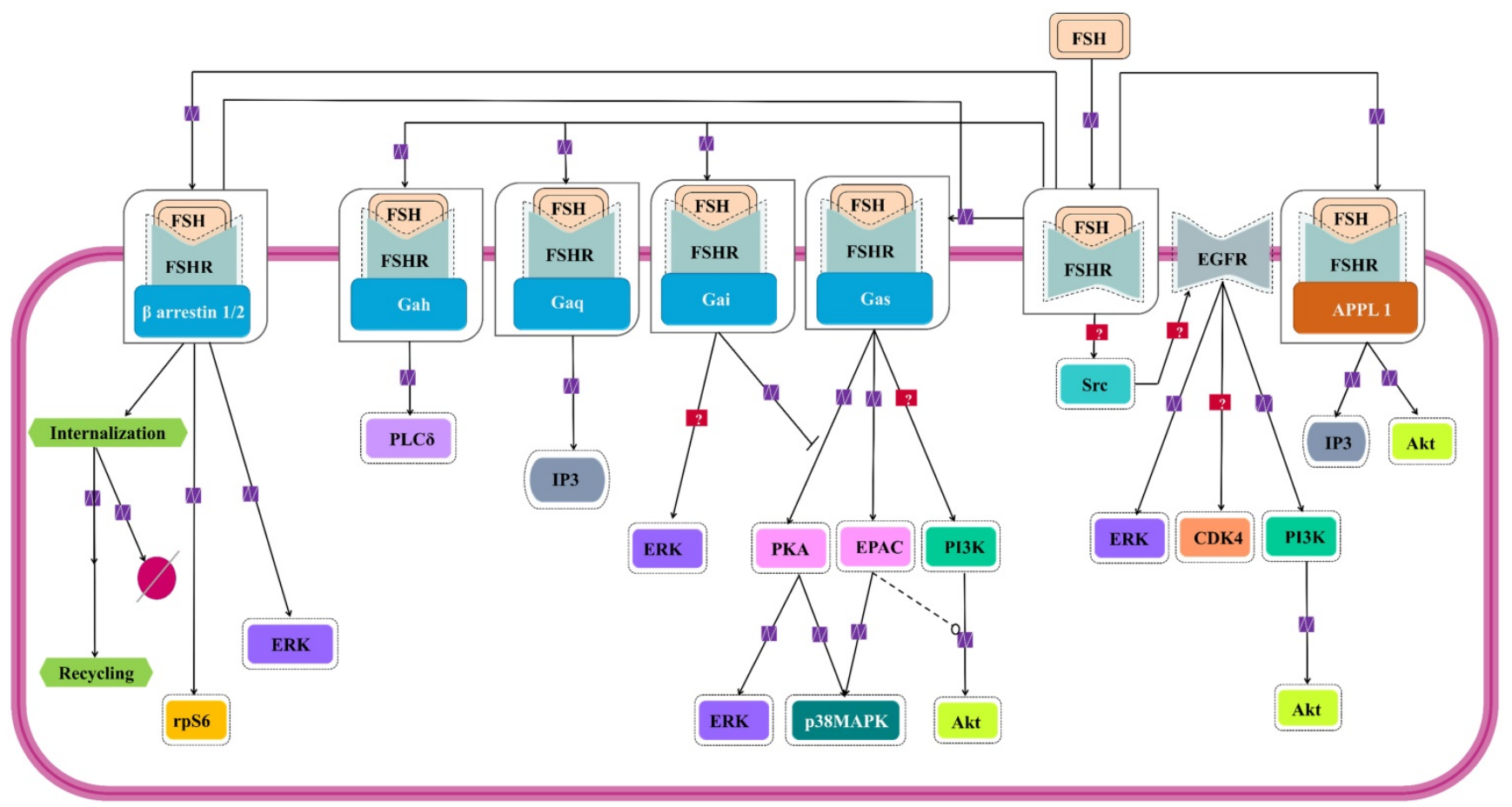

Figure 5. Signaling cascades triggered by FSH-FHSR system in target cells. Besides the main Gas/cAMP/protein kinase A (PKA) pathway that has been believed to be the mainstay of FSH signal transduction within the target cells, accumulating evidences over the last decade show that FSHR can also engage APPL1-mediated signaling, EGFR transactivation and $\beta$-arrestin-dependent pathways. Solid lines represent facilitatory outcomes whereas, the dotted ones pertain to the inhibitory results. Adapted from Bloaguen et al. [111] under CC-BY License.

\section{The Canonical Gas-dependent Pathway}

The well-studied Gas pathway shows that FSHFSHR interactions lead to coupling of the receptor to Gas subunit inducing adenylate cyclase activity to produce cAMP [112]. cAMP, in turn, activates the downstream effectors like protein kinase A (PKA) and EPAC (exchange protein directly activated by cAMP). Binding of cAMP to PKA releases the catalytic subunits of the latter, that phosphorylates several targets, both cytosolic and nuclear [113, 114]. FSH mediated activation of cytosolic ERK-MAPK pathway is believed to be PKA dependent $[115,116]$. PKAmediated phosphorylation of the protein phosphatase (PTP) leads to disruption of the PTP-ERK complex resulting in increased ERK phosphorylation given that MEK is constitutively phosphorylated [117]. Along another pathway, PKA activates Raf1, thereby, inducing MEK followed by ERK [118,119]. FSH induced MAPK p38 phosphorylation is also PKA dependent $[120,121]$. As a downstream effector of FSH-FSHR activation, EPAC binds accumulated cAMP to trigger GDP to GTP exchange on Rap1, and its consequent, activation in the granulosa and surface epithelial cells of ovary $[23,121]$. Activated Rap1 consequently, actuates ERK, p38 and Akt [23,122]. The pathway has been depicted schematically in Figure 6 .

\section{$\beta$-arrestin-dependent Pathway}

Starting off as a pathway for desensitizing and recycling FSHR, $\beta$-arrestin pathway, gradually received the recognition of one with adapters and transducers of FSH-FSHR signaling [123] (Figure 7). It has been shown in different models that binding of FSH to FSHR gets phosphorylated by G protein-coupled receptor kinases (GRKs) 2, 3, 5, and 6 $[116,124-127]$, at the serine-threonine clusters in C-terminal intracellular domain, particularly by GRK 2 [116]. GRK 5 and 6 mediated FSHR phosphorylation evoked responses similar to those found with GRK 2, albeit to a lesser extent [116]. $\beta$-arrestin mediated receptor recycling elicits $G$ protein independent transduction of signals, not only, through FSHR, but also through several other 7TMRs [116,123,128,129]. Interestingly, unlike, the rapid, transient nature of $G$ protein mediated transduced signals, the ones being cascaded through $\beta$-arrestin pathway are gradual and sustained [116]. Besides, $\beta$-arrestin mediate rpS6 phosphorylation in HEK293 cells in response to FSHR activation [130].

\section{$\mathrm{PI} 3 \mathrm{~K} / \mathrm{mTOR}$ pathway}

Involvement of $\mathrm{PI} 3 \mathrm{~K} / \mathrm{mTOR}$ pathway as an effector route for FSH-FSHR mediated signaling has been substantiated through several studies. All the pathways show PI3K activation and PIP3 accumulation [131-133] and several of downstream signal cascades that involves Akt activation [24,28,131,133-139] leading to phosphorylation and deactivation of GSK3 $\beta[28,140]$ and AMPK [141] and 
inactivation of transcription factors, FoxO3a and FoxO1 [133,134,136,138,139,142] (Figure 8). However, in a contradictory report, PTEN, the negative regulator of PIP3 accumulation, has been noted to be upregulated by FSH stimulation, thus, preventing FSH-mediated cell proliferation [133]. In addition to PI3K/PIP3 pathway inducing the mTOR phosphorylation [132,138], FSH-FSHR activated ERK pathway also triggers mTOR signaling via lifting of negative regulation on Rheb through TSC2 phosphorylation $[134,143,144]$. Activated mTOR pathway ensures p70S6K activity [132,133,138,143, 144] resulting in phosphorylation of rpS6 [132,134, 144]. Active mTOR phosphorylates to inactivate 4E-BP1, the negative regulator of protein translation [134]. Simultaneous rpS6 activation and 4E-BP1 inactivation indicate that FSH-FSHR stimulation also modulates effector molecules at the level of protein translation, besides, influencing transcription.

\section{FSH controlled nuclear events}

Modulation of expressions of genes involved in steroidogenesis by FSH is a well-established [145]. Besides, it is also known to control expressions of genes involved in cell cycle through the regulation of Smad proteins [146]. This FSH mediated regulation of nuclear events is as complex as its cytosolic effector signal cascading. Interestingly, the activated cytosolic effector molecules undergo nuclear translocation to take the signal transduction triggered by FSH-FSHR stimulation across the nucleus leading to gene expression. Catalytic subunit of FSH-activated PKA translocates to nucleus to set off CREB by phosphorylating it on S133, thus, regulating the expressions of the genes containing cAMP response element (CRE) in their upstream region $[117,140]$. Nuclear PKA also facilitates the recruitment of Activator Protein-1 (AP-1) at its cognate binding regions upstream of the open reading frames [147].

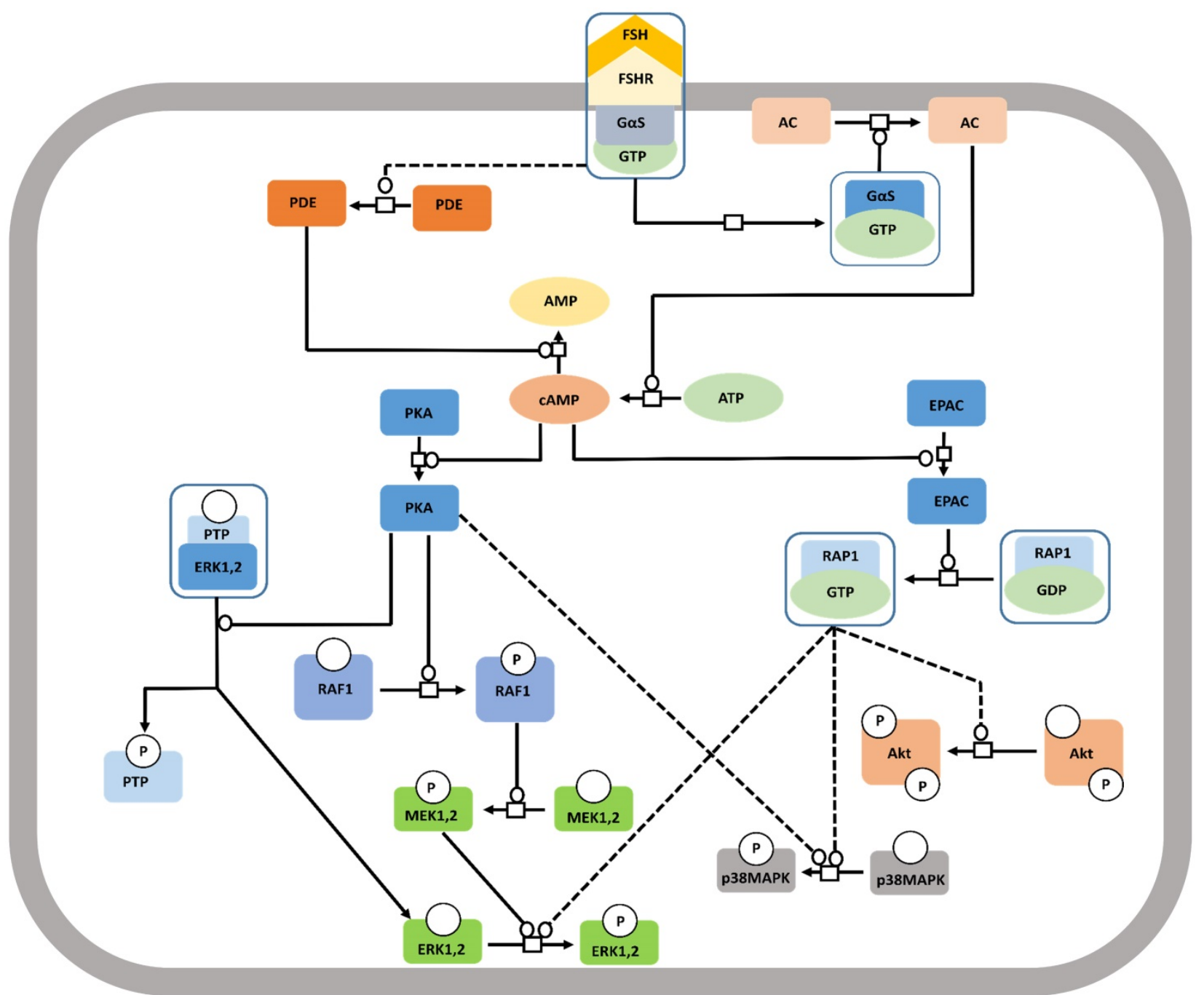

Figure 6. Canonical Gas/cAMP/PKA pathway at FSHR in target cells. The Gas/cAMP/PKA pathway has been the most studied and is associated with various intracellular events. It is now acknowledged that PKA is not the sole target of cAMP accumulation. Indeed, EPAC is also activated upon FSH stimulation. Both PKA and EPAC contribute to the activation of MAPK, ERK and P38, whereas EPAC also leads to Akt activation. Solid lines represent facilitatory outcomes whereas, the dotted ones pertain to the inhibitory results. Adapted from Gloaguen et al. [111] under CC-By License. 
PKA extends its effect beyond modulation of promoters to post-translational histone modifications, like, histone H3 phosphorylation and acetylation [148] favoring cell division [149]. In an indirect modus operandi to modulate gene expression, cytosolic PKA binds to retinoic acid receptor alpha to inhibit its nuclear translocation, thereby, modulating the expressions of the genes under the regulation of this transcription factor [150]. Akt also affects gene expression in PKA independent manner. As mentioned earlier, activated Akt phosphorylates the transcription factors, FoxO1a and FoxO3a resulting in their nuclear exclusion and concomitant MDM2dependent HIF-1a activation and repression of pro-apoptotic genes, respectively [28,131,136,138,139]. Akt mediated GSK3 $\beta$ deactivation indirectly supports LEF dependent transcription [24,140]. Akt also promotes nuclear translocation of NFkB [151]. Likewise, activated MAP kinases, ERK and p38 are reported to affect transcriptional activities regulated by AP-1 and CREB [152]. All these nuclear events which are affected by FSH-FSHR stimulation are depicted in Figure 9.

\section{FSHR interacting proteins}

Until now we elaborately described about the pathways that get activated mostly through second messengers due to the interaction between FSH and FSHR. FSHR being a member of the GPCR family, this mode of activating signaling cascade is expected. Interestingly, FSH-FSHR interaction can also adopt alternative pathways to transduce signals and this largely, involves direct physical interaction of certain proteins with FSHR (Figure 10). A number of such interacting proteins have been identified and shown to influence FSH-mediated intracellular signaling [153]. APPL1 is one such protein found to interact with the first and second intracellular loops of FSHR, concomitantly, mediating PI3K and Akt activation [136]. Residues K376, L377 and F382 in the first intracellular loop of FSHR are involved in the interaction with APPL1, with K376 being particularly, indispensable for linking activated FSHR to the inositol-phosphatase pathway and intracellular calcium mobilization [154]. Although, several studies link APPL1 with FSH triggered intra-cellular calcium accumulation, yet, the extent to which this association is required remains yet to be deciphered [155-158]. APPL1-FSHR interaction is also associated with nuclear exclusion of FoxO1a through Akt-dependent phosphorylation [159]. Along another pathway, FoxO1a is reported to exhibit direct interaction with FSHR, which prevent its nuclear translocation. Scaffolding protein 14-3-3 $\tau$ is yet another factor known to interact with the second intracellular loop of

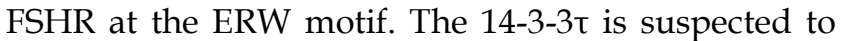
compete with Gas binding at the spot based on the reported observation that overexpression of the scaffold protein reduced FSH-induced cAMP accumulation $[159,160]$.

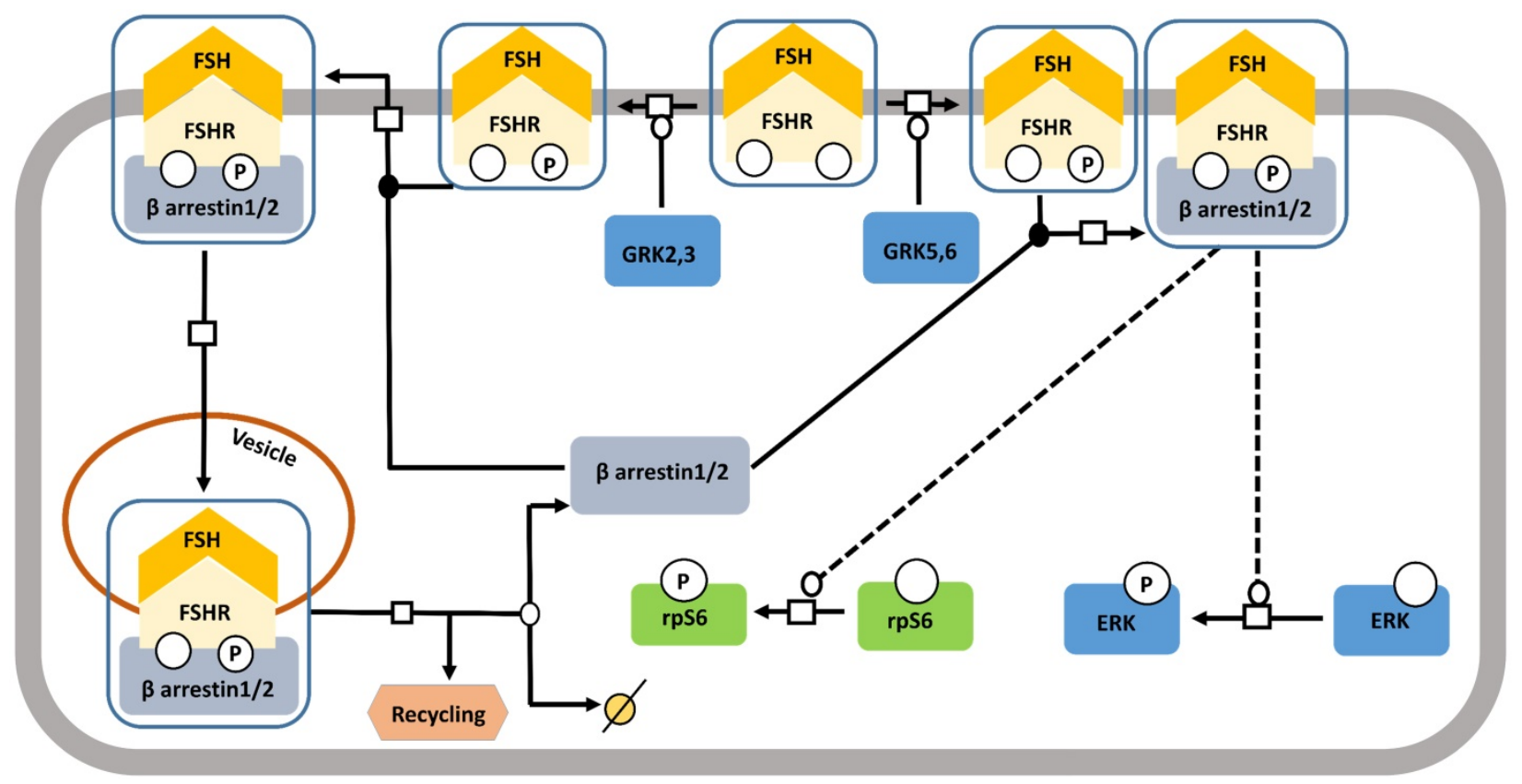

Figure 7. FSH- induced $\beta$-arrestin-dependent pathway. Initially, the perception of $\boldsymbol{\beta}$-arrestins' role was restricted to the control of desensitization of FSHR and its recycling. This view has progressively evolved towards a more general role of $\beta$-arrestins as adapters and transducers leading to the activation of MAPK, ERK and rpS6 independent of G proteins upon FSH stimulation. GRK2/3 and GRK $5 / 6$ control the fate of the activated FSHR (i.e., desensitization or signaling) presumably through phosphorylation of distinct serine and threonines within the receptor's C-tail. Solid lines represent facilitatory outcomes whereas, the dotted ones pertain to the inhibitory results. Adapted from Gloaguen et al. [111] under CC-BY License. 


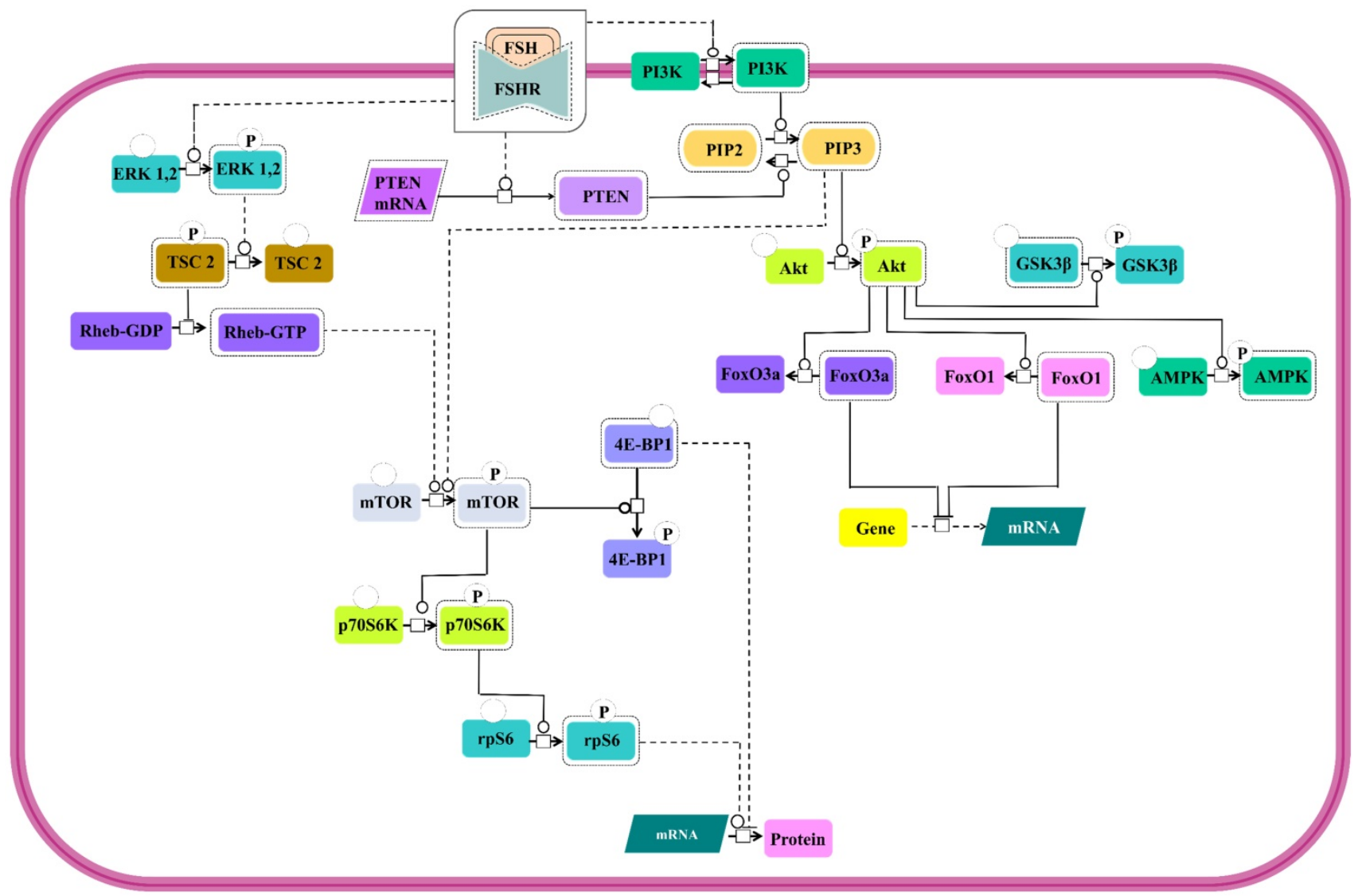

Figure 8. PI3K/mTOR signaling at FSHR in target cells. The PI3K/mTOR pathway plays an important role in FSH-induced actions, including proliferation, regulation of gene expression as well as protein translation. Solid lines represent facilitatory outcomes whereas, the dotted ones pertain to the inhibitory results. Adapted from Gloaguen et al. [111] Under CC-BY License.

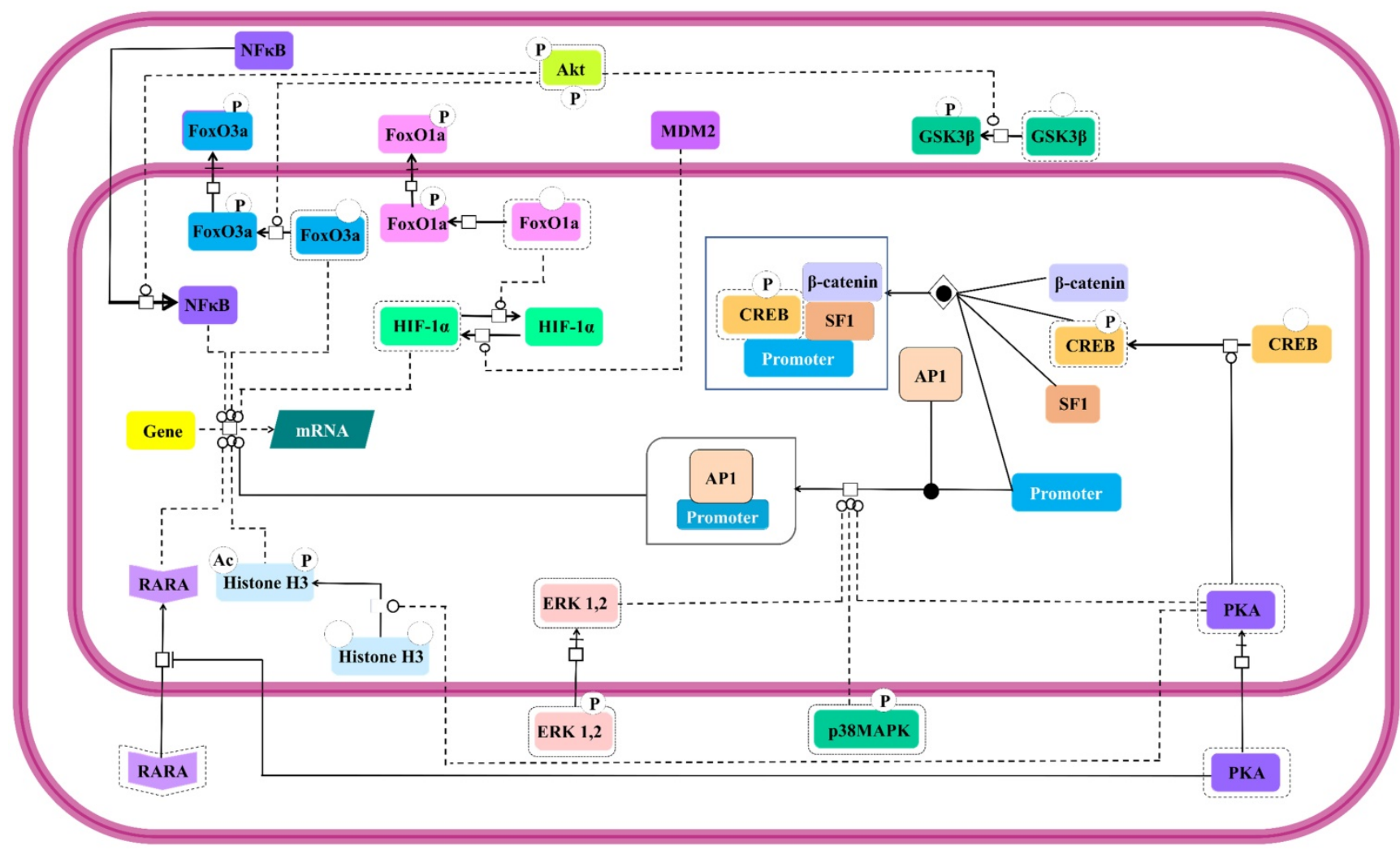

Figure 9. Nuclear events controlled by FSH. Gene transcription has long been known to be affected by FSH. Multiple signaling pathways that are activated upon stimulation (i.e., PKA, p38, ERK and Akt) subsequently trigger the activation or suppression of the activities of various transcription factors within the nucleus. Solid lines represent facilitatory outcomes whereas, the dotted ones pertain to the inhibitory results. Adapted from Gloaguen et. al. [111] under CC-BY License. 


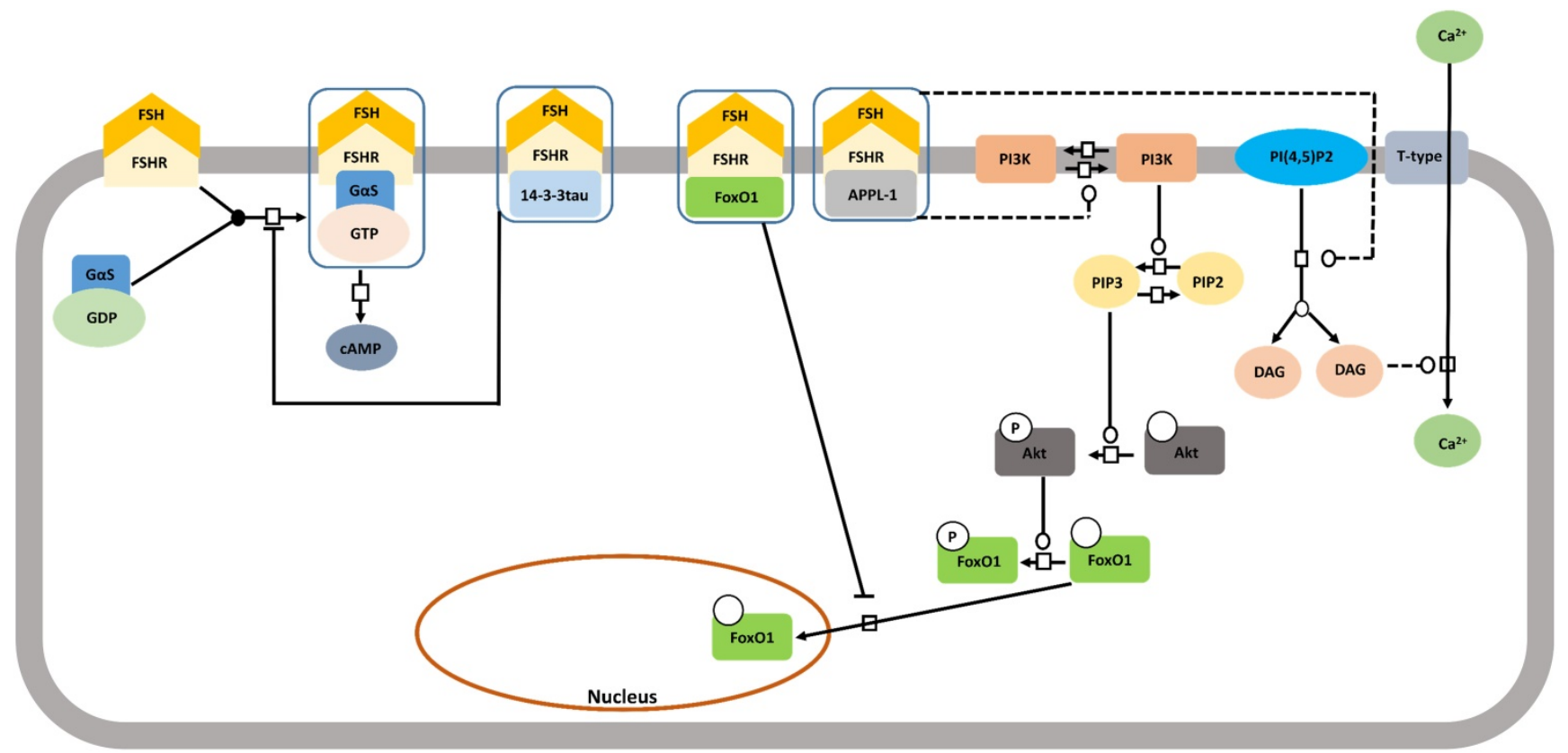

Figure 10. Proteins interacting with FSHR thus impacting the signalling pathway. A number of proteins interact with FSHR thus affecting FSH-induced signaling pathways. These include 14-3-3tau, FoxOI and APPL1, the latter two being involved in the control of the PI3K/Akt pathway downstream of FSHR. Solid lines represent facilitatory outcomes whereas, the dotted ones pertain to the inhibitory results. Adapted from Gloaguen et al. [111] under CC-BY License.

\section{Potential therapeutic implication of FSH-FSHR system}

The association of identified mutations in FSHR with specific cellular functional has enabled this information to be utilized in identifying therapeutic targets and designing of novel therapeutics. For example, pharmacophore (Org 41841) was designed to bind FSHR at a site other than that used by FSH and improve the membrane localization of the receptor in the presence of an $\mathrm{Ala}^{189} \mathrm{Val}$ mutation, known for misrouting the receptor and retaining it in the endoplasmic reticulum [161]. Such studies hold promise for identifying treatment modalities for reproductive abnormalities owing to non-functioning or dysfunctional FSHR. Similar studies to allow a better assessment of the potential of FSH-FSHR system as therapeutic targets have been conducted. For example, a study validating the expression of FSHR in renal carcinoma cells in response to sunitinib [108]. FSH-FSHR signaling promotes angiogenesis. Degarelix, a gonadotropin-releasing hormone receptor antagonist, was used to block FSH production in a multi-treated metastatic colon cancer patient with encouraging results [162]. Urbanska and colleagues evaluated a $\mathrm{T}$ cell-based immunotherapy targeting FSHR with promising results that warrant further investigations [163]. In addition, small inhibitory RNA- (siRNA) mediated modulation of the FSH-FSHR system is also being explored. In vitro observations revealed a possibility of slowing the growth of FSH-responsive tumors through siRNA- mediated silencing of FSHR3 in mouse ovarian cancer cell lines [164]. Taken together, these evidences show that the FSH-FSHR could be a very effective anticancer target.

\section{Future directions in modulating FSH-FSHR signaling}

The elevated FSH levels of ovarian cancer corroborate with the increased expression of FSHR in several cancers. Upregulated endothelial FSHR levels in cancers are associated with vascular remodeling and tumor angiogenesis, whereas, its epithelial counterpart facilitates cell proliferation, migration and invasion [165]. Therefore, FSHR has emerged as a potential anti-cancer therapeutic target and prognostic tool. However, to the best of our knowledge no clinical trial has been performed for the clinical application of FSH-FSHR in treatment of cancer. However, there are several clinical trials have been performed or underway for the application of stem cells to treat different types of cancers [166]. A number of small non-peptide ligands, such as: thiazolidinediones, benzamides, and dihydropyridine Org 24444-0, have also been explored for their effects on FSHR-induced signaling [167-169]. In contrast, non-peptide ligands, such as tetrahydroquinolines, antagonized cAMP production without affecting FSH-FSHR interactions [170] have been explored. Single chain analogs of FSH have also been developed to ameliorate the effects of inactivating mutations of the FSH-FSHR signaling system [171]. However, these compounds still need to be tested in clinical trials. In 
addition, antibody-mediated targeting of FSH-FSHR system is another actively explored avenue for modulating this FSH/FSHR signaling system [172174]. FSH/FSHR antagonists in the form of nanobodies are also being explored as potential modulators of this signaling system [175]. Last, but not the least are the pepducins [176] and aptamers [177], two classes of pharmacological modulators, which are based on their performance as GPCR modulators, deserve thorough evaluation in the context of FSH-FSHR signaling. Altogether, these evidences show that modulation of FSH-FSHR signalling for anti-cancer therapeutic outcomes are past the speculative stage and warrants for in-detail investigations for being developed into effective treatment options.

\section{Summary}

FSH/FSHR signaling controls several crucial biological pathways, therefore, malfunctioning of this signaling system is bound to culminate into several disorders, including cancer. This review mainly covers the connection between FSH and FSHR signaling and its role in cancer. Attempts were made to provide a comprehensive understanding of the various aspects under the control of the FSH/FSHR signaling system. This included the effect on stem cell maintenance and propagation, as well as sources of variations in the functioning of FSH or FSHR (or both). Studies reporting various mutations, polymorphisms, and alternatively spliced variants of FSHR have correlated these products with their respective phenotypes, clearly suggesting that such genetic alterations may result in infertility. Discussion on in vitro functional studies provides valuable information on FSH-FSHR interactions at the molecular level. Few mutations have been reported in either subunit of FSH and may lead to pathological implications. Comparatively, FSHR has a greater number of mutations, some resulting in gain-offunction, while others resulting in a loss-of-function. These mutations affect hormone binding ability or hormone-induced signaling ability by introducing structural changes in the receptor. Various polymorphisms of FSHR have been associated with risks of different types of cancers. Finally, the therapeutic implications of this information have been documented with a positive future perspective on its potential applications.

Many aspects of the FSH-FSHR signaling system require better insight and clarifications, for which detailed studies are needed. Moreover, along with the understanding of the alterations in the signaling mechanisms that affect the prognosis of cancer, it is important to devise protocols of translating this foundational knowledge to clinical applications. This review has put together several aspects of FSH-FSHR signaling which are highly informative and provide quick reference to facilitate the designing of elaborate studies with the objectives dedicated towards harnessing the therapeutic aspects and potentials of FSH in fertility and disorders especially cancer.

\section{Acknowledgements}

\section{Author Contributions}

Drs. SH, HA and SS designed and wrote the review article. AS, PR and SSK review the article in depth, made the appropriate changes and edited the article. All authors have read the final version and approved its contents.

\section{Funding}

This work was supported by NIH grants T32 HL134644 and R25 GM133328 to SSK.

\section{Competing Interests}

The authors have declared that no competing interest exists.

\section{References}

1. Pierce JG, Parsons TF. Glycoprotein hormones: Structure and function. Annu Rev Biochem. 1981; 50: 465-95.

2. Richards JS. Maturation of ovarian follicles: actions and interactions of pituitary and ovarian hormones on follicular cell differentiation. Physiol Rev. 1980; 60(1): 51-89.

3. McLachlan RI, Wreford NG, Robertson DM, de Kretser DM. Hormonal control of spermatogenesis. Trends Endocrinol Metab. 1995; 6(3): 95-101.

4. Gharib SD, Chin WW, Wierman ME, Shupnik MA. Molecular biology of the pituitary gonadotropins. Endocr Rev. 1990; 11(1): 177-99.

5. Ulloa-Agirre A, Timossi C, Damian-Matsumara P, Dias JA Role of Glycosylation on Folding, Assembly, and Secretion of hFSH. Endocrine. 1999; 11(3): 205-15.

6. Ulloa-Aguirre A, Maldonado A, Damián-Matsumura P, Timossi C. Endocrine regulation of gonadotropin glycosylation. Arch Med Res. 2001; 32(6): 520-32.

7. Jiang X, Liu H, Chen X, Chen PH, Fischer D, Sriraman V, et al. Structure of follicle-stimulating hormone in complex with the entire ectodomain of its receptor. Proc Natl Acad Sci U S A. 2012; 109(31): 12491-6.

8. Fan QR, Hendrickson WA. Structural Biology of Glycoprotein Hormones and their Receptors. Endocrine. 2005; 26(3): 179-88.

9. Baenziger JU, Green ED. Pituitary glycoprotein hormone oligosaccharides: Structure, synthesis and function of the asparagine-linked oligosaccharides on lutropin, follitropin and thyrotropin. BBA - Rev Biomembr. 1988; 947(2): 287306.

10. Stockell Hartree A, Renwick AGC. Molecular structures of glycoprotein hormones and functions of their carbohydrate components. Biochem J. 1992; 287(3): 665-79.

11. Ulloa-Aguirre A, Timossi C Structure-function relationship of folliclestimulating hormone and its receptor. Hum Reprod Update. 1998; 4(3): 260-83.

12. Timossi CM, De Tomasi JB, Zambrano E, González R, Ulloa-Aguirre A. A naturally occurring basically charged human follicle-stimulating hormone (FSH) variant inhibits FSH-induced androgen aromatization and tissue-type plasminogen activator enzyme activity in vitro. Neuroendocrinology. 1998; 67(3): 153-63.

13. Loreti N, Fresno C, Barrera D, Andreone L, Albarran SL, Fernandez EA, et al. The glycan structure in recombinant human FSH affects endocrine activity and global gene expression in human granulosa cells. Mol Cell Endocrinol. 2013; 366(1): 68-80.

14. Huhtaniemi IT, Aittomaki K. Mutations of follicle-stimulating hormone and its recepto: effects on gonadal function. Eur J Endocrinol. 1998; 138: 473-81.

15. Simoni M, Gromoll J, Nieschlag E. The follicle-stimulating hormone receptor: Biochemistry, molecular biology, physiology, and pathophysiology. Endocr Rev. 1997; 18(6): 739-73.

16. Jiang X, Dias JA, He X. Structural biology of glycoprotein hormones and their receptors: Insights to signaling. Mol Cell Endocrinol. 2014; 382(1): 424-51. 
17. Pascali $F$ De, Tréfier $A$, Landomiel $F$, Bozon $V$, Bruneau $G$, Yvinec $R$, et al. Follicle-stimulating hormone receptor: advances and remaining challenges. Int Rev Cell Mol Biol. 2018; 338: 1-58.

18. Sairam MR, Babu PS. The tale of follitropin receptor diversity: A recipe for fine tuning gonadal responses? Mol Cell Endocrinol [Internet]. 2007; 260-262(1): 163-71.

19. Bhartiya D, Singh J. FSH-FSHR3-stem cells in ovary surface epithelium: Basis for adult ovarian biology, failure, aging, and cancer. Reproduction. 2015; 149(1): R35-48

20. Ulloa-Aguirre A, Uribe A, Zariñán T, Bustos-Jaimes I, Pérez-Solis MA, Dias JA. Role of the intracellular domains of the human FSH receptor in GaS protein coupling and receptor expression. Mol Cell Endocrinol. 2007; 260-262: 153-62.

21. Yarney TA, Jiang L, Khan H, Macdonald EA, Laird DW, Sairam MR. Molecular cloning, structure, and expression of a testicular follitropin receptor with selective alteration in the carboxy terminus that affects signaling function. Mol Reprod Dev. 1997; 48(4): 458-70.

22. Casarini L, Crépieux P. Molecular mechanisms of action of FSH. Front Endocrinol (Lausanne). 2019; 10: 1-10

23. Wayne CM, Fan HY, Cheng X, Richards JAS. Follicle-stimulating hormone induces multiple signaling cascades: Evidence that activation of Rous sarcoma oncogene, RAS, and the epidermal growth factor receptor are critical for granulosa cell differentiation. Mol Endocrinol. 2007; 21(8): 1940-57.

24. Gonzalez-Robayna IJ, Falender AE, Ochsner S, Firestone GL, Richards JS. Follicle-stimulating hormone (FSH) stimulates phosphorylation and activation of protein kinase $\mathrm{B}$ (PKB/Akt) and serum and glucocorticoid-induced kinase (Sgk): Evidence for A kinase-independent signaling by FSH in granulosa cells. Mol Endocrinol. 2000; 14(8): 1283-300.

25. Richards JS. New signaling pathways for hormones and cyclic adenosine 3',5'-monophosphate action in endocrine cells. Mol Endocrinol. 2001; 15(2): $209-18$.

26. Hunzicker-Dunn M, Maizels ET. FSH signaling pathways in immature granulosa cells that regulate target gene expression: Branching out from protein kinase A. Cell Signal. 2006; 18(9): 1351-9.

27. Kuo SW, Ke FC, Chang GD, Lee MT, Hwang JJ. Potential role of follicle-stimulating hormone (FSH) and transforming growth factor (TGF $\beta 1$ ) in the regulation of ovarian angiogenesis. J Cell Physiol. 2011; 226(6): 1608-19.

28. Alam H, Week J, Maizels E, Park Y, Lee EJ, Ashcroft M, et al. Role of the phosphatidylinositol-3-kinase and extracellular regulated kinase pathways in the induction of hypoxia-inducible factor (HIF)-1 activity and the HIF-1 target vascular endothelial growth factor in ovarian granulosa cells in response to follicle-. Endocrinology. 2009; 150(2): 915-28.

29. Sullivan RR, Faris BR, Eborn D, Grieger DM, Cino-Ozuna AG, Rozell TG. Follicular expression of follicle stimulating hormone receptor variants in the ewe. Reprod Biol Endocrinol. 2013; 11(1): 1-8.

30. Themmen APN, Huhtaniemi IT. Mutations of gonadotropins and gonadotropin receptors: Elucidating the physiology and pathophysiology of pituitary-gonadal function. Endocr Rev. 2000;21(5):551-83.

31. Sairam MR, Jiang LG, Yarney TA, Khan H. Follitropin signal transduction: Alternative splicing of the FSH receptor gene produces a dominant negative form of receptor which inhibits hormone action. Biochem Biophys Res Commun. 1996; 226(3): 717-22.

32. Touyz RM, Jiang L, Sairam MR. Follicle-stimulating hormone mediated calcium signaling by the alternatively spliced growth factor type I receptor. Biol Reprod. 2000; 62(4): 1067-74.

33. Babu PS, Jiang L, Sairam AM, Touyz RM, Sairam MR. Structural features and expression of an alternatively spliced growth factor type I receptor for follitropin signaling in the developing ovary. Mol Cell Biol Res Commun. 1999; 2(1): 21-7.

34. Babu PS, Krishnamurthy H, Chedrese PJ, Sairam MR. Activation of extracellular-regulated kinase pathways in ovarian granulosa cells by the novel growth factor type 1 follicle-stimulating hormone receptor: Role in hormone signaling and cell proliferation. J Biol Chem. 2000; 275(36): 27615-26.

35. Li Y, Ganta S, Cheng C, Craig R, Ganta RR, Freeman LC. FSH stimulates ovarian cancer cell growth by action on growth factor variant receptor. Mol Cell Endocrinol. 2007; 267(1-2): 26-37.

36. Lusson J, Vieau D, Hamelin J, Day R, Chretein M, Seidah NG. cDNA structure of the mouse and rat subtilisin / kexin-like PC5: A candidate proprotein convertase expressed in endocrine and nonendocrine cells. Proc Natl Acad Sci. 1993; 90: 6691-5

37. Perez Mayorga M, Gromoll J, Behre HM, Gassner C, Nieschlag E, Simoni M. Ovarian response to follicle-stimulating hormone (FSH) stimulation depends on the FSH receptor genotype. J Clin Endocrinol Metab. 2000; 85(9): 3365-9.

38. Simoni M, Nieschlag E, Gromoll J. Isoforms and single nucleotide polymorphism of the FSH receptor gene: Implications for human reproduction. Hum Reprod Update. 2002; 8(5): 413-21.

39. Bhartiya D, Parte S, Patel H, Sriraman K, Zaveri K, Hinduja I. Novel Action of FSH on Stem Cells in Adult Mammalian Ovary Induces Postnatal Oogenesis and Primordial Follicle Assembly. Stem Cells Int. 2015; 2016: 1-13.

40. Martin J, Woods D, Tilly J. Implications and Current Limitations of Oogenesis from Female Germline or Oogonial Stem Cells in Adult Mammalian Ovaries. Cells. 2019; 8(2): 93.

41. Patel H, Bhartiya D. Testicular Stem Cells Express Follicle-Stimulating Hormone Receptors and Are Directly Modulated by FSH. Reprod Sci. 2016; 23(11): 1493-508
42. Patel H, Bhartiya D. Direct action of FSH on testicular stem cells. Stem Cell Res Ther. 2019;1 0(1): 10-2

43. Bhartiya D, Anand S, Kaushik A, Sharma D. Chapter-6. Stem Cells in the Mammalian Gonads. Stem Cells. Ratajczak MZ, editor. Switzerland AG 2019: Springer Nature. 2019. 109

44. Bhartiya D, Patel H. Ovarian stem cells - resolving controversies. J Assist Reprod Genet. 2018; 35(3):393-8.

45. Johnson J, Canning J, Kaneko T, Pru JK, Tilly JL. Germline stem cells and follicular renewal in the postnatal mammalian ovary. Nature. 2004; 428(6979): 145-50.

46. Virant-Klun I, Skutella T, Hren M, Gruden K, Cvjeticanin B, Vogler A, et al. Isolation of small ssea-4-positive putative stem cells from the ovarian surface epithelium of adult human ovaries by two different methods. Biomed Res Int. 2013; 2013: 690415

47. Virant-Klun I. Functional Testing of Primitive Oocyte-like Cells Developed in Ovarian Surface Epithelium Cell Culture from Small VSEL-like Stem Cells: Can They Be Fertilized One Day? Stem Cell Rev Reports. 2018; 14(5): 715-21.

48. Bhartiya D, Sriraman K, Parte S, Patel H. Ovarian stem cells: Absence of evidence is not evidence of absence. J Ovarian Res. 2013; 6(1):1

49. Bhartiya D, Unni S, Parte S, Anand S. Very small embryonic-like stem cells: Implications in reproductive biology. Biomed Res Int. 2013; 2013: 682326.

50. Parte S, Bhartiya D, Telang J, Daithankar V, Salvi V, Zaveri K, et al. Detection, characterization, and spontaneous differentiation in vitro of very small embryonic-like putative stem cells in adult mammalian ovary. Stem Cells Dev. 2011; 20(8): 1451-64

51. Parte S, Bhartiya D, Manjramkar DD, Chauhan A, Joshi A. Stimulation of ovarian stem cells by follicle stimulating hormone and basic fibroblast growth factor during cortical tissue culture. J Ovarian Res. 2013; 6(1): 1-10.

52. Bhartiya D, Hinduja I, Patel H, Bhilawadikar R. Making gametes from pluripotent stem cells--a promising role for very small embryonic-like stem cells. Reprod Biol Endocrinol. 2014; 12: 114.

53. Bhartiya D, Anand S, Patel H, Parte S. Making gametes from alternate sources of stem cells: past, present and future. Reprod Biol Endocrinol. 2017; 15(1): 89.

54. Bhartiya D, Anand S, Kaushik A, Sharma D. Stem Cells in the Mammalian Gonads. Adv Exp Med Biol. 2019; 1201: 109-23.

55. Bhartiya D, Sriraman K, Gunjal P, Modak H. Gonadotropin treatment augments postnatal oogenesis and primordial follicle assembly in adult mouse ovaries? J Ovarian Res. 2012; 5(1): 32.

56. Patel H, Bhartiya D, Parte S, Gunjal P, Yedurkar S, Bhatt M. Follicle stimulating hormone modulates ovarian stem cells through alternately spliced receptor variant FSH-R3. J Ovarian Res. 2013; 6: 52.

57. Sriraman K, Bhartiya D, Anand S, Bhutda S. Mouse ovarian very small embryonic-like stem cells resist chemotherapy and retain ability to initiate oocyte-specific differentiation. Reprod Sci. 2015; 22(7): 884-903.

58. Lei L, Spradling AC. Female mice lack adult germ-line stem cells but sustain oogenesis using stable primordial follicles. Proc Natl Acad Sci U S A. 2013; 110(21): 8585-90.

59. Zhang $\mathrm{H}$, Liu L, Li X, Busayavalasa $\mathrm{K}$, Shen $\mathrm{Y}$, Hovatta O, Gustafsson J Å, Liu $\mathrm{K}$. Life-long in vivo cell-lineage tracing shows that no oogenesis originates from putative germline stem cells in adult mice. Proc Natl Acad Sci U S A. 2014; 111(50): 17983-8.

60. Siegel ET, Kim HG, Nishimoto HK, Layman LC. The molecular basis of impaired follicle-stimulating hormone action: Evidence from human mutations and mouse models. Reprod Sci. 2013; 20(3): 211-33.

61. Dierich A, Sairam MR, Monaco L, Fimia GM, Gansmuller A, Lemeur M, et al. Impairing follicle-stimulating hormone (FSH) signaling in vivo: Targeted disruption of the FSH receptor leads to aberrant gametogenesis and hormonal imbalance. Proc Natl Acad Sci U S A. 1998; 95(23): 13612-7.

62. Abel MH, Wootton AN, Wilkins V, Huhtaniemi I, Knight PG, Charlton HM. The effect of a null mutation in the follicle-stimulating hormone receptor gene on mouse reproduction. Endocrinology. 2000; 141(5): 1795-803.

63. McDonald R, Sadler C, Kumar TR. Gain-of-function genetic models to study FSH action. Front Endocrinol (Lausanne). 2019; 10: 28

64. McLean DJ, Russell LD, Griswold MD. Biological activity and enrichment of spermatogonial stem cells in vitamin A-deficient and hyperthermia-exposed testes from mice based on colonization following germ cell transplantation. Biol Reprod. 2002; 66(5): 1374-9.

65. Kojima Y, Kominami K, Dohmae K, Nonomura N, Miki T, Okuyama A, et al. Cessation of spermatogenesis in juvenile spermatogonial depletion (jsd/jsd) mice. Int J Urol. 1997; 4(5): 500-7.

66. Paradisi R, Natali F, Fabbri R, Battaglia C, Seracchioli R, Venturoli S. Evidence for a stimulatory role of high doses of recombinant human follicle-stimulating hormone in the treatment of male-factor infertility. Andrologia. 2014; 46(9): 1067-72.

67. Oduwole $\mathrm{OO}$, Peltoketo $\mathrm{H}$, Huhtaniemi IT. Role of follicle-stimulating hormone in spermatogenesis. Front Endocrinol (Lausanne). 2018; 9: 763.

68. Ding LJ, Yan GJ, Ge QY, Yu F, Zhao X, Diao ZY, et al. FSH acts on the proliferation of type a spermatogonia via Nur77 that increases GDNF expression in the Sertoli cells. FEBS Lett. 2011; 585(15): 2437-44.

69. Bellaïche J, Goupil AS, Sambroni E, Lareyre JJ, Le Gac F. Gdnf-Gfra1 pathway is expressed in a spermatogenetic-dependent manner and is regulated by Fsh in a fish testis. Biol Reprod. 2014; 91(4): 1-12.

70. Anand S, Bhartiya D, Sriraman K, Patel H, and Manjramkar DD. Very small embryonic-like stem cells survive and restore spermatogenesis after busulphan treatment in mouse testis. 2014; 7:1-16. 
71. Anand S, Bhartiya D, Sriraman K, Mallick A. Underlying Mechanisms that Restore Spermatogenesis on Transplanting Healthy Niche Cells in Busulphan Treated Mouse Testis. Stem Cell Rev Reports. 2016; 12(6): 682-97.

72. Zuba-Surma EK, Kucia M, Wu W, Klich I, Jr. JWL, Ratajczak J, et al. Very Small Embryonic- Like stem cells (VSELs) are present in adult murine organs: ImageStream based morphological analysis and distribution studies. Cytom A. 2008; 73A(12): 1116-27.

73. James K, Bhartiya D, Ganguly R, Kaushik A, Gala K, Singh P, et al. Gonadotropin and steroid hormones regulate pluripotent very small embryonic-like stem cells in adult mouse uterine endometrium. J Ovarian Res. 2018; 11(1):83.

74. Ayob AZ, Ramasamy TS. Cancer stem cells as key drivers of tumour progression. J Biomed Sci. 2018; 25(1):1-18.

75. Arnold CR, Mangesius J, Skvortsova II, Ganswindt U. The Role of Cancer Stem Cells in Radiation Resistance. Front Oncol. 2020; 10:164.

76. Yu Z, Pestell TG, Lisanti MP, Pestell RG. Cancer Stem Cells. Int J Biochem Cell Biol. 2012; 44(12): 2144-2151.

77. Zhang Z, Zhu Y, Lai Y, Wu X, Feng Z, Yu Y, et al. Follicle-stimulating hormone inhibits apoptosis in ovarian cancer cells by regulating the OCT4 stem cell signaling pathway. Int J Oncol. 2013; 43(4): 1194-204.

78. Song K, Dai L, Long X, Wang W, Di W. Follicle-stimulating hormone promotes the proliferation of epithelial ovarian cancer cells by activating sphingosine kinase. Sci Rep. 2020; 10(1): 1-13.

79. Bhartiya D, Patel H, Ganguly R, Shaikh A, Shukla Y, Sharma D, et al. Novel Insights into Adult and Cancer Stem Cell Biology. Stem Cells Dev. 2018; 27(22): 1527-39.

80. Chrusciel M, Ponikwicka-Tyszko D, Wolczynski S, Huhtaniemi I, Rahman NA. Extragonadal FSHR expression and function-is it real? Front Endocrinol (Lausanne). 2019; 10: 32.

81. Kaushik A, Bhartiya D. Pluripotent Very Small Embryonic-Like Stem Cells in Adult Testes - An Alternate Premise to Explain Testicular Germ Cell Tumors. Stem Cell Rev Reports. 2018; 14(6): 793-800.

82. Tanabe S. Signaling involved in stem cell reprogramming and differentiation. World J Stem Cells. 2015; 7(7): 992-8

83. Heng D, Wang Q, Ma X, Tian Y, Xu K, Weng X et al. Role of OCT4 in the Regulation of FSH-Induced Granulosa Cells Growth in Female Mice. Front Endocrinol (Lausanne). 2020; 10: 915.

84. Liu L, Zhang J, Fang C, Zhang Z, Feng Y, Xi X. OCT4 mediates FSH-induced epithelial-mesenchymal transition and invasion through the ERK1/2 signaling pathway in epithelial ovarian cancer. Biochem Biophys Res Commun. 2015; 461(3): 525-32.

85. Patel H, Bhartiya D, Parte S, Gunjal P, Yedurkar S, Bhatt M. Follicle stimulating hormone modulates ovarian stem cells through alternately spliced receptor variant FSH-R3. J Ovarian Res. 2013; 6: 52

86. Couse JF, Yates MM, Sanford R, Nyska A, Nilson JH, Korach KS. Formation of cystic ovarian follicles associated with elevated luteinizing hormone requires estrogen receptor- $\beta$. Endocrinology. 2004; $145(10)$ : 4693-702.

87. Ferlin A, Pengo M, Selice R, Salmaso L, Garolla A, Foresta C. Analysis of single nucleotide polymorphisms of FSH receptor gene suggests association with testicular cancer susceptibility. Endocr Relat Cancer. 2008; 15(2): 429-37.

88. Ludwig AH, Murawska M, Panek G, Timorek A, Kupryjanczyk J. Androgen, progesterone, and FSH receptor polymorphisms in ovarian cancer risk and outcome. Endocr Relat Cancer. 2009; 16(3): 1005-16.

89. Mariani S, Salvatori L, Basciani S, Arizzi M, Franco G, Petrangeli E, et al. Expression and Cellular Localization of Follicle-Stimulating Hormone Receptor in Normal Human Prostate, Benign Prostatic Hyperplasia and Prostate Cancer. J Urol. 2006; 175(6): 2072-7.

90. Ben-Josef E, Yang SY, Ji TH, Bidart JM, Garde S V., Chopra DP, et al. Hormone-refractory prostate cancer cells express functional folliclestimulating hormone receptor (FSHR). J Urol. 1999; 161(3): 970-6.

91. Parrott JA, Doraiswamy V, Kim G, Mosher R, Skinner MK. Expression and actions of both the follicle stimulating hormone receptor and the luteinizing hormone receptor in normal ovarian surface epithelium and ovarian cancer. Mol Cell Endocrinol. 2001; 172(1-2): 213-22.

92. Bose CK. Follicle stimulating hormone receptor in ovarian surface epithelium and epithelial ovarian cancer. Oncol Res. 2008; 17(5): 231-8.

93. Bose CK. Role of nerve growth factor and FSH receptor in epithelial ovarian cancer. Reprod Biomed Online. 2005; 11(2): 194-7.

94. Zhang Z, Jia L, Feng Y, Zheng W. Overexpression of follicle-stimulating hormone receptor facilitates the development of ovarian epithelial cancer. Cancer Lett. 2009; 278(1): 56-64.

95. Huang Y, Jin H, Liu Y, Zhou J, Ding J, Cheng KW, et al. FSH inhibits ovarian cancer cell apoptosis by up-regulating survivin and down-regulating PDCD6 and DR5. Endocr Relat Cancer. 2011; 18(1): 13-26.

96. Huang $\mathrm{Y}$, Hua $\mathrm{K}$, Zhou X, Jin H, Chen X, Lu X, et al. Activation of the $\mathrm{PI} 3 \mathrm{~K} / \mathrm{AKT}$ pathway mediates FSH-stimulated VEGF expression in ovarian serous cystadenocarcinoma. Cell Res. 2008; 18(7): 780-91.

97. Chen J, Bai M, Ning C, Xie B, Zhang J, Liao H, et al. Gankyrin facilitates follicle-stimulating hormone-driven ovarian cancer cell proliferation through the PI3K/AKT/HIF-1a/cyclin D1 pathway. Oncogene. 2015; 35(19): 2506-17.

98. Castro-Fernández C, Maya-Núñez G, Méndez JP. Regulation of follicle-stimulating and luteinizing hormone receptor signaling by "regulator of G protein signaling" proteins. Endocrine. 2004; 25(1): 49-54.

99. Zeng H, Zhao D, Yang S, Datta K, Mukhopadhyay D. Heterotrimeric Gaq/Ga11 proteins function upstream of vascular endothelial growth factor
(VEGF) receptor-2 (KDR) phosphorylation in vascular permeability factor/VEGF signaling. J Biol Chem. 2003; 278(23): 20738-45.

100. Radu A, Pichon C, Camparo P, Antoine M, Allory Y, Couvelard A, et al. Expression of follicle-stimulating hormone receptor in tumor blood vessels. $\mathrm{N}$ Engl J Med. 2010; 363(17): 1621-30.

101. Pawlikowski M, Fuss-Chmielewska J, Jaranowska M, Pisarek H, Kubiak R, Winczyk K. Expression of follicle stimulating hormone receptors (FSHR) in thyroid tumours - A marker of malignancy? Thyroid Res. 2015; 8(1): 6-9.

102. Pawlikowski M, Jaranowska M, Pisarek H, Kubiak R, Fuss-Chmielewska J, Winczyk K. Ectopic expression of follicle-stimulating hormone receptors in thyroid tumors. Arch Med Sci. 2015; 11(6): 1314-7.

103. Pawlikowski M, Pisarek H, Kubiak R, Jaranowska M, Stępień H. Immunohistochemical detection of FSH receptors in pituitary adenomas and adrenal tumors. Folia Histochem Cytobiol. 2012; 50(3): 325-30.

104. Sardella C, Russo D, Raggi F, Lombardi M, Urbani C, Brogioni S, et al. Ectopic expression of FSH receptor isoforms in neoplastic but not in endothelial cells frompancreatic neuroendocrine tumors. J Endocrinol Invest. 2013; 36(3): 174-9.

105. Lenhard M, Lennerová T, Ditsch N, Kahlert S, Friese K, Mayr D, et al. Opposed roles of follicle-stimulating hormone and luteinizing hormone receptors in ovarian cancer survival. Histopathology. 2011; 58(6): 990-4.

106. Heublein S, Vrekoussis T, Mayr D, Friese K, Lenhard M, Jeschke U, et al. Her-2/neu expression is a negative prognosticator in ovarian cancer cases that do not express the follicle stimulating hormone receptor (FSHR). J Ovarian Res. 2013; 6(1):6.

107. Siraj A, Desestret V, Antoine M, Fromont G, Huerre M, Sanson M, et al. Expression of follicle-stimulating hormone receptor by the vascular endothelium in tumor metastases. BMC Cancer. 2013; 13: 246.

108. Siraj MA, Pichon C, Radu A, Ghinea N. Endothelial follicle stimulating hormone receptor in primary kidney cancer correlates with subsequent response to sunitinib. J Cell Mol Med. 2012; 16(9): 2010-6.

109. Means AR, Macdougall E, Soderling TR, Corbin JD. Testicular Adenosine $3^{\prime}: 5^{\prime}$-Monophosphate-dependent Protein Kinase. J OP BIOLOQIC L Chem. 1974; 249(4): 1231-8.

110. Dattatreyamurty B, Figgs LW, Reichert LE. Physical and functional association of follitropin receptors with cholera toxin-sensitive guanine nucleotide-binding protein. J Biol Chem. 1987; 262(24): 11737-45.

111. Gloaguen P, Crépieux P, Heitzler D, Poupon A, Reiter E. Mapping the follicle-stimulating hormone-induced signaling networks. Front Endocrinol (Lausanne). 2011; 2: 45.

112. Northup JK, Sternweis PC, Smigel MD, Schleifer LS, Ross EM, Gilman AG. Purification of the regulatory component of adenylate cyclase. Proc Natl Acad Scd. 1980; 77(11): 6516-20.

113. Rangel Aldao R, Rosen OM. Dissociation and reassociation of the phosphorylated and nonphosphorylated forms of adenosine $3^{\prime}: 5^{\prime}$ monophosphate dependent protein kinase from bovine cardiac muscle. J Biol Chem. 1976; 251(11):3 375-80

114. Landmark BF, Fauske B, Eskild W, Skålhegg B, Lohmann SM, Hansson V, et al. Identification, characterization, and hormonal regulation of $3^{\prime}, 5^{\prime}$-cyclic adenosine monophosphate dependent protein kinases in rat sertoli cells. Endocrinology. 1991; 129(5): 2345-54.

115. Crepieux P, Marion S, Martinat N, Fafeur V, Vern Y Le, Kerboeuf D, et al. The ERK-dependent signalling is stage-specifically modulated by $\mathrm{FSH}$, during primary Sertoli cell maturation. Oncogene. 2001; 20: 4696-709.

116. Kara E, Crépieux P, Gauthier C, Martinat N, Piketty V, Guillou F, et al. A phosphorylation cluster of five serine and threonine residues in the C-terminus of the follicle-stimulating hormone receptor is important for desensitization but not for $\beta$-arrestin-mediated ERK activation. Mol Endocrinol. 2006; 20(11): 3014-26.

117. Cottom I, Salvador LM, Maizels ET, Reierstad S, Park Y, Carr DW, et al. Follicle-stimulating hormone activates extracellular signal-regulated kinase but not extracellular signal-regulated kinase kinase through a $100-\mathrm{kDa}$ phosphotyrosine phosphatase. J Biol Chem. 2003; 278(9): 7167-79.

118. Yang P, Roy SK. A novel mechanism of FSH regulation of DNA synthesis in the granulosa cells of hamster preantral follicles: Involvement of a protein kinase C-mediated MAP kinase 3/1 self-activation loop. Biol Reprod. 2006; 75(1): 149-57.

119. Ongeri EM, Verderame MF, Hammond JM. The TATA binding protein associated factor $4 \mathrm{~b}$ (TAF4b) mediates FSH stimulation of the IGFBP-3 promoter in cultured porcine ovarian granulosa cells. Mol Cell Endocrinol. 2007; 278(1-2): 29-35

120. Maizels ET, Cottom J, Jones JCR, Hunzicker-dunn M. Follicle stimulating hormone (FSH) activates the p38 mitogen-activated protein kinase pathway, inducing small heat shock protein phosphorylation and cell rounding in immature rat ovarian granulosa cells. Endocrinology. 1998; 139(7): 3353-6.

121. Yu FQ, Han CS, Yang W, Jin X, Hu ZY, Liu YX. Activation of the p38 MAPK pathway by follicle-stimulating hormone regulates steroidogenesis in granulosa cells differentially. J Endocrinol. 2005; 186(1): 85-96.

122. Choi JH, Chen CL, Poon SL, Wang HS, Leung PCK. Gonadotropin-stimulated epidermal growth factor receptor expression in human ovarian surface epithelial cells: Involvement of cyclic AMP-dependent exchange protein activated by cAMP pathway. Endocr Relat Cancer. 2009; 16(1): 179-88.

123. Reiter E, Lefkowitz RJ. GRKs and $\beta$-arrestins: roles in receptor silencing, trafficking and signaling. Trends Endocrinol Metab. 2006; 17(4): 159-65.

124. Nakamura K, Krupnick JG, Benovic JL, Ascoli M. Signaling and phosphorylation-impaired mutants of the rat follitropin receptor reveal an 
activation- and phosphorylation-independent but arrestin- dependent pathway for internalization. J Biol Chem. 1998; 273(38): 24346-54.

125. Lazari MDFM, Liu X, Nakamura K, Benovic JL, Ascoli M. Role of G protein-coupled receptor kinases on the agonist-induced phosphorylation and internalization of the follitropin receptor. Mol Endocrinol. 1999; 13(6): 866-78.

126. Troispoux C, Guillou F, Elalouf JM, Firsov D, Iacovelli L, De Blasi A, et al. Involvement of $\mathrm{G}$ protein-coupled receptor kinases and arrestins in desensitization to follicle-stimulating hormone action. Mol Endocrinol. 1999; 13(9): 1599-614.

127. Krishnamurthy H, Kishi H, Shi M, Galet C, Bhaskaran RS, Hirakawa T, et al. Postendocytotic Trafficking of the Follicle-Stimulating Hormone (FSH)-FSH Receptor Complex. Mol Endocrinol. 2003; 17(11): 2162-76.

128. Wehbi V, Decourtye J, Piketty V, Durand G, Reiter E, Maurel MC. Selective modulation of follicle-stimulating hormone signaling pathways with enhancing equine chorionic gonadotropin/antibody immune complexes. Endocrinology. 2010; 151(6): 2788-99.

129. Tranchant T, Durand G, Gauthier $C$, Crépieux $P$, Ulloa-Aguirre $A$, Royère $D$, et al. Preferential $\beta$-arrestin signalling at low receptor density revealed by functional characterization of the human FSH receptor A189 V mutation. Mol Cell Endocrinol. 2011; 331(1): 109-18.

130. Wehbi V, Tranchant T, Durand G, Musnier A, Decourtye J, Piketty V, et al. Partially deglycosylated equine LH preferentially activates $\beta$-arrestin-dependent signaling at the follicle-stimulating hormone receptor. Mol Endocrinol. 2010; 24(3): 561-73.

131. Park Y, Maizels ET, Feiger ZJ, Alam H, Peters CA, Woodruff TK, et al. Induction of cyclin D2 in rat granulosa cells requires FSH-dependent relief from FOXO1 repression coupled with positive signals from Smad. J Biol Chem. 2005; 280(10): 9135-48.

132. Musnier A, Heitzler D, Boulo T, Tesseraud S, Durand G, Lécureuil C, et al. Developmental regulation of p70 S6 kinase by a G protein-coupled receptor dynamically modelized in primary cells. Cell Mol Life Sci. 2009; 66(21): 3487503.

133. Dupont J, Musnier A, Decourtye J, Boulo T, Lécureuil C, Guillou H, et al. FSH-stimulated PTEN activity accounts for the lack of FSH mitogenic effect in prepubertal rat Sertoli cells. Mol Cell Endocrinol. 2010; 315(1-2): 271-6.

134. Alam H, Maizels ET, Park Y, Ghaey S, Feiger ZJ, Chandel NS, et al. Follicle-stimulating Hormone Activation of Hypoxia-inducible Factor-1 by the Phosphatidylinositol 3-Kinase/AKT/Ras Homolog Enriched in Brain (Rheb)/Mammalian Target of Rapamycin (mTOR) Pathway Is Necessary for Induction of Select Protein Markers of Follic. J Biol Chem. 2004; 279(19): 1943140 .

135. Meroni SB, Riera MF, Pellizzari EH, Galardo MN, Cigorraga SB. FSH activates phosphatidylinositol 3-kinase/protein kinase $B$ signaling pathway in 20-day-old Sertoli cells independently of IGF-I. J Endocrinol. 2004; 180(2): 25765 .

136. Nechamen CA, Thomas RM, Cohen BD, Acevedo G, Poulikos PI, Testa JR, et al. Human follicle-stimulating hormone (FSH) receptor interacts with the adaptor protein APPL1 in HEK 293 cells: Potential involvement of the PI3K pathway in FSH signaling. Biol Reprod. 2004; 71(2): 629-36.

137. McDonald CA, Millena AC, Reddy S, Finlay S, Vizcarra J, Khan SA, et al. Follicle-stimulating hormone-induced aromatase in immature rat sertoli cells requires an active phosphatidylinositol 3-kinase pathway and is inhibited via the mitogen-activated protein kinase signaling pathway. Mol Endocrinol. 2006; 20(3): 608-18.

138. Chen YJ, Hsiao PW, Lee MT, Mason JI, Ke FC, Hwang JJ. Interplay of P13K and CAMP/PKA signaling, and rapamycin-hypersensitivity in TGF $\beta 1$ enchancement of FSH-stimulated steroidogenesis in rat ovarian granulosa cells. J Endocrinol. 2007; 192(2): 405-19.

139. Fan HY, Liu Z, Cahill N, Richards JAS. Targeted disruption of Pten in ovarian granulosa cells enhances ovulation and extends the life span of luteal cells. Mol Endocrinol. 2008; 22(9): 2128-40.

140. Fan HY, O'Connor A, Shitanaka M, Shimada M, Liu Z, Richards JAS. $\beta$-catenin (CTNNB1) promotes preovulatory follicular development but represses LH-mediated ovulation and luteinization. Mol Endocrinol. 2010; 24(8): 152942.

141. Kayampilly PP, Menon KMJ. Follicle-stimulating hormone inhibits adenosine 5 '-monophosphate- activated protein kinase activation and promotes cell proliferation of primary granulosa cells in culture through an akt-dependent pathway. Endocrinology. 2009; 150(2): 929-35.

142. Cunningham MA, Zhu Q, Unterman TG, Hammond JM. Follicle-Stimulating Hormone Promotes Nuclear Exclusion of the Forkhead Transcription Factor FoxOla via Phosphatidylinositol 3-Kinase in Porcine Granulosa Cells. Endocrinology. 2003; 144(12): 5585-94.

143. Kayampilly PP, Menon KMJ. Follicle-stimulating hormone increases tuberin phosphorylation and mammalian target of rapamycin signaling through an extracellular signal-regulated kinase-dependent pathway in rat granulosa cells. Endocrinology. 2007; 148(8): 3950-7.

144. Lécureuil C, Tesseraud S, Kara E, Martinat N, Sow A, Fontaine I, et al. Follicle-stimulating hormone activates $\mathrm{p} 70$ ribosomal protein $\mathrm{S} 6$ kinase by protein kinase A-mediated dephosphorylation of Thr 421/Ser 424 in primary sertoli cells. Mol Endocrinol. 2005; 19(7): 1812-20.

145. Escamilla-Hernandez R, Little-Ihrig L, Zeleznik AJ. Inhibition of rat granulosa cell differentiation by overexpression of Gaq. Endocrine. 2008; 33(1): 21-31.

146. Wang W, Chen X, Li X, Wang L, Zhang H, He Y, et al. Interference RNA-based silencing of endogenous SMAD4 in porcine granulosa cells resulted in decreased FSH-mediated granulosa cells proliferation and steroidogenesis. Reproduction. 2011; 141(5): 643-51.

147. Yang W, Lu CL, Yu FQ, Liu T, Hu ZY, Liu YX. Mitogen-activated protein kinase regulates FSH-induced expression of tissue-type plasminogen activator through an activator protein 1 response element. Endocrine. 2008; 34(1-3): 101-7.

148. Salvador LM, Park Y, Cottom J, Maizels ET, Jones JCR, Schillace R V., et al. Follicle-stimulating Hormone Stimulates Protein Kinase A-mediated Histone H3 Phosphorylation and Acetylation Leading to Select Gene Activation in Ovarian Granulosa Cells. J Biol Chem. 2001; 276(43): 40146-55.

149. Hans F, Dimitrov S. Histone H3 phosphorylation and cell division. Oncogene. 2001; 20(24): 3021-7.

150. Santos NC, Kim KH. Activity of retinoic acid receptor-alpha is directly regulated at its protein kinase $\mathrm{A}$ sites in response to follicle-stimulating hormone signaling. Endocrinology. 2010; 151(5): 2361-72.

151. Wang $\mathrm{Y}$, Chan S, Tsang BK. Involvement of inhibitory nuclear factor- $\mathrm{KB}$ (NFKB)-independent NFKB activation in the gonadotropic regulation of X-linked inhibitor of apoptosis expression during ovarian follicular development in vitro. Endocrinology. 2002; 143(7): 2732-40.

152. Cameron MR, Foster JS, Bukovsky A, Wimalasena J. Activation of mitogen-activated protein kinases by gonadotropins and cyclic adenosine 5'-monophosphates in porcine granulosa cells. Biol Reprod. 1996; 55(1): 111-9.

153. Dias JA, Nechamen CA, Atari R. Identifying protein interactors in gonadotropin action. Endocrine. 2005; 26(3): 241-7.

154. Thomas RM, Nechamen CA, Mazurkiewicz JE, Ulloa-Aguirre A, Dias JA. The adapter protein APPL1 links FSH receptor to inositol 1,4,5-trisphosphate production and is implicated in intracellular $\mathrm{Ca} 2+$ mobilization. Endocrinology. 2011; 152(4): 1691-701.

155. Flores JA, Veldhuis JD, Leong DA. Follicle-stimulating hormone evokes an increase in intracellular free calcium ion concentrations in single ovarian (Granulosa) cells. Endocrinology. 1990; 127(6): 3172-9.

156. Jayes FCL, Day RN, Garmey JC, Urban RJ, Zhang G, Veldhuis JD. Calcium Ions Positively Modulate Follicle-Stimulating Hormone- and Exogenous Cyclic 3'-5'-Adenosine Monophosphate-Driven Transcription of the P450 (SCC) Gene in Porcine Granulosa Cells. Endocrinology. 2000; 141(7): 2377-84

157. Lai TH, Lin YF, Wu FC, Tsai YH. Follicle-stimulating hormone-induced Gah/phospholipase C- $\delta 1$ signaling mediating a noncapacitative $\mathrm{Ca} 2+$ influx through T-type Ca2+ channels in rat sertoli cells. Endocrinology. 2008; 149(3): 1031-7.

158. Lin YF, Tseng MJ, Hsu HL, Wu YW, Lee YH, Tsai YH. A novel follicle-stimulating hormone-induced $\mathrm{Gah} /$ phospholipase C- $\delta 1$ signaling pathway mediating rat Sertoli cell Ca2+-influx. Mol Endocrinol. 2006; 20(10): 2514-27.

159. Dias JA, Mahale SD, Nechamen CA, Davydenko O, Thomas RM, Ulloa-Aguirre A. Emerging roles for the FSH receptor adapter protein APPL1 and overlap of a putative 14-3-3 $\mathrm{\tau}$ interaction domain with a canonical G-protein interaction site. Mol Cell Endocrinol. 2010; 329(1-2): 17-25.

160. Cohen BD, Nechamen CA, Dias JA. Human follitropin receptor (FSHR) interacts with the adapter protein 14-3-3t. Mol Cell Endocrinol. 2004; 220(1-2): $1-7$

161. Janovick JA, Maya-Núñez G, Ulloa-Aguirre A, Huhtaniemi IT, Dias JA, Verbost P, et al. Increased Plasma Membrane Expression of Human FollicleStimulating Hormone Receptor by a Small Molecule Thienopyr(im) idine. Mol Cell Endocrinol. 2009; 298(1-2): 84-8.

162. Ghiringhelli F, Isambert N, Ladoire S. Degarelix as a new antiangiogenic agent for metastatic colon cancer? World J Gastroenterol. 2013; 19(5): 769-72.

163. Urbanska K, Stashwick C, Poussin M, Powell DJ. Follicle-Stimulating hormone receptor as a target in the redirected T-cell therapy for cancer. Cancer Immunol Res. 2015; 3(10): 1130-7.

164. Bose CK. Follicle stimulating hormone receptor (FSHR) antagonist and epithelial ovarian cancer (EOC). J Exp Ther Oncol. 2007; 6(3): 201-4.

165. Lizneva D, Rahimova A, Kim SM, Atabiekov I, Javaid S, Alamoush B, et al. FSH beyond fertility. Front Endocrinol (Lausanne). 2019; 10: 136

166. Chu DT, Nguyen TT, Tien NLB, Tran DK, Jeong JH, Anh PG, et al. Recent Progress of Stem Cell Therapy in Cancer Treatment: Molecular Mechanisms and Potential Applications. Cells. 2020; 9(3): 1-19.

167. Sriraman V, Denis D, De Matos D, Yu H, Palmer S, Nataraja S. Investigation of a thiazolidinone derivative as an allosteric modulator of follicle stimulating hormone receptor: Evidence for its ability to support follicular development and ovulation. Biochem Pharmacol. 2014; 89(2): 266-75.

168. Yu HN, Richardson TE, Nataraja S, Fischer DJ, Sriraman V, Jiang X, et al. Discovery of substituted benzamides as follicle stimulating hormone receptor allosteric modulators. Bioorganic Med Chem Lett. 2014; 24(9): 2168-72.

169. Van Koppen CJ, Verbost PM, Van De Lagemaat R, Karstens WJF, Loozen HJJ, Van Achterberg TAE, et al. Signaling of an allosteric, nanomolar potent, low molecular weight agonist for the follicle-stimulating hormone receptor. Biochem Pharmacol. 2013; 85(8): 1162-70.

170. van Straten NCR, van Berkel THJ, Demont DR, Karstens WJF, Merkx R, Oosterom $\mathrm{J}$, et al. Identification of substituted 6-amino-4phenyltetrahydroquinoline derivatives: Potent antagonists for the follicle-stimulating hormone receptor. J Med Chem. 2005; 48: 1697-700.

171. Sugahara T, Pixley MR, Minami S, Perlas E, Ben-Menahem D, Hsueh AJW, et al. Biosynthesis of a biologically active single peptide chain containing the human common $a$ and chorionic gonadotropin $\beta$ subunits in tandem. Proc Natl Acad Sci. 1995; 92(6): 2041-5. 
172. Hutchings CJ, Koglin M, Olson WC, Marshall FH. Opportunities for therapeutic antibodies directed at G-protein-coupled receptors. Nat Rev Drug Discov. 2017; 16(11): 787-810.

173. Mujić-Delić A, De Wit RH, Verkaar F, Smit MJ. GPCR-targeting nanobodies: Attractive research tools, diagnostics, and therapeutics. Trends Pharmacol Sci. 2014; 35(5): 247-55.

174. Staus DP, Strachan RT, Manglik A, Pani B, Kahsai AW, Kim TH, et al. Allosteric nanobodies reveal the dynamic range and diverse mechanisms of G-protein-coupled receptor activation. Nature. 2016; 535(7612): 448-52.

175. Crepin R, Veggiani G, Diender S, Beugnet A, Planeix F, Pichon C, et al Whole-cell biopanning with a synthetic phage display library of nanobodies enabled the recovery of follicle-stimulating hormone receptor inhibitors. Biochem Biophys Res Commun. 2017; 493(4): 1567-72.

176. Carr R, Benovic JL. From biased signalling to polypharmacology: Unlocking unique intracellular signalling using pepducins. Biochem Soc Trans. 2016; 44(2): 555-61.

177. Kahsai AW, Wisler JW, Lee J, Ahn S, Cahill TJ, Dennison SM, et al. Conformationally selective RNA aptamers allosterically modulate the $\beta$ 2-Adrenoceptor. Nat Chem Biol. 2016; 12(9): 709-16. 